\title{
Three-dimensional Finite Element Formulation and Scalable Domain Decomposition for High Fidelity Rotor Dynamic Analysis
}

\author{
Anbhax Datea \\ DLORET Corsoration \\ AFDD at Ames Reseerch Center \\ Wofett Field, OA $940 \%$ \\ Wayne Johnson \\ Aeromechanics Branch \\ NASA Atres Regearch Center \\ Montet Field, CA 94035
}

American Helicopter Society 65 th Armul Forum

Grapevine, TX, May 27 20, 2009

\begin{abstract}
This paper has two objectives. The first objective is to formulate a 3 -dimensional Finte Element Model for the dynamic analysis of helicopter rotor blades. The second objective is to implement and analyze a dual-primal iterative substructuring based Krylov solwar, that is parallel and scalable, for the solution of the 3-D FEM analysis. The numerical and patallel scalability of the solver is studied using two prototype problems - one for ideal hover (symmetric) and one for a transient forward flight (non-symmetric) - both carried out on up to 48 processors. In both hover and forward fight conditions, a perfect linear speed-up is obserwed, for a given problem size, up to the point of substructure optimality. Substructure optimality and the linear parallel speed-up range are both shown to depend on the problem size as well as on the selection of the coarse problem. With a larger problem size, linear speed up is restored up to the new subtructure optimality. The solver also scales with problem size even though this conclusion is premature given the small prototype grids considered in this study.
\end{abstract}

\section{INTRODUCTION}

One bundret years ago what is now caller the Poncuté-Steklov operator was introduced. This operatot, which govern the interiace of a problen genemted by decompesing a arger problem into many smaler subproblems, Wave spectral properties that are superior to

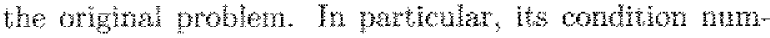
ber grows at at rote that is an order lower than that of the orighal problum. Every modem method of terative substucumg is based on one or many variational forms of this operator.

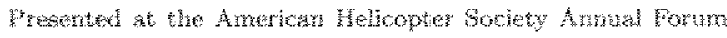
60, Crapewine, Thera, May 27-20, 200
The wend stbstructumg and the wethod was introduced fify years ago by Prententek $[1,2]$. Together with Denke [3], Argyrs and Kelsey $[4]$, and Thror to al [5], they hid the foundatoms of displacement and force finte eloment andysis of partioned stmucures. These partitoned methots wewe the only avenues to obtan results tor praction strutures for which the original urobtem far exeded the capacity of computers at the time. The method of substructures have remaized the fastost (time), most efich (nemory), most rebole (achrate), and most lexibe (heterogenots nhyse und propertes) method of partitioned andyst of latge sche strictures. The motern nathods of primal and dua themetse substructuring bave them ongin and genesis in these origne contributhons - established lown before the advent of paratel computers.

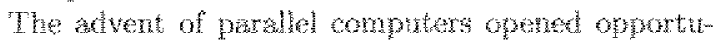


nity for solving each partioned substruture in a sepa rate procesor. A straight forward implementaton, howwer, leads to a clead end. First, the high conditon number and lack of sparsity of the intertace equation by itsel poses s signifeant challenge for convergence. Second, the total interface size grows both with problem size and with partitions, protucing a chanatic increase in the re cured number of terations. The recomition, that a ha nite elenent representation of the substrublure intertace

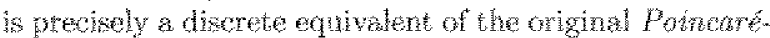
Steklov operator, allows the matheratical theoris of domain decomposition to be brotght to bear directly towards the rexolution of this key problem. Today, pto cedures are avalable which precondition the interface and solves it iteratively, in a paralle and scalable manner, requrityg only local substwetrie calculations. These procednres are called berative substricturing methods. Their objective is to provide optimal nmerical scalabilty, te. to ensure that the condition number of the prenondivoned interface does not grow wth the number of substructures and grows at most polyogarithmically whin mesh refinement with each substructure.

The wathenatical theory of fonaly ecompostion provides scalatle algorthms for wo broad classes of partitioning: overlapping and non-overappiry [6]. The overlapping partitonitig leads to addine Schwarz methots, which are variants of block Jacobi precondtioners. These are widely med in thid mechanics, but are of litte on no importance in structural mechanics - due to the very high condition numbers $\left(10^{*}-10^{10}\right)$ and high bandwidth of practical structures. Structural medtanice use nowoverlapping partitioning. They lead to iterative substruc turing methods, a name borrowed from, and as explanned earlier, indicative of the deep connections to the long and successful tradition of substructuring.

The growth of the mathematical theory of itera. tive substructuring can be traced to the seminal work of Agoskov et al. $\{7,8\}$ and Bramble et al. $[9]$ in the mid-1980s. The fommer provided a detailed analysis of the pomente-stehow operator. The latter provided one of the eatliest scalable interfoce preconditioners tor a 2 nd order thptic poblen with homogenoue coeffcents. Subsequett algorithmic developments in this area have contimued through the $1990 \mathrm{~s}$ and 2000 sthe interested reader is referred to monographs by Quateroni and Vall [10? and Toelli and Widund (11) etlminemes in the inereging application of these methods for Hoh Performance Comptting (HPC) based large scale problems of computational mechanics $[12,13]$. Today, NeutrantNewnann type balaneing nethods known as Balancing Doman Deconvestion with Constraing (BDDC) (see [14] and references theren) and the DirichetDrichet wpe dual methods mown as linte Elentrit Tearing and Intergration (FWT) wethods (see [15] and revenes thereis) prowde scable preconditionets that are optirat for up to th order problems that incinde highy discontrinous and heterogenow sudoring.

Both the Neumann-Neumann snd FET mothods

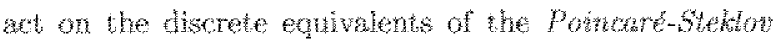

interface operator. The former acts on primal prim. The larter acts on its dud fom (exphined later). Both are based on smultaneons Dirichlet and Neumann solves whin wach substructure one for precondtonng and one for residua calculation w... only in reverse order to one another. Note that the Nemann solves - which lie at the heart of these methods - are non-muerthate for foating substructures that arise naturuly from mutiple

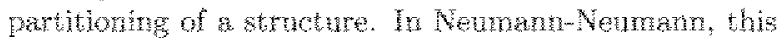
singularity occus in the preonditioner, in wet the sin gularty occurs is be restidat calculaton.

The primary objectwo of this paper is to apply an advanced mult-lewel FWT method, the FET-Dual Primal (DP) wethod, pioneed by what et al. [15, 16], fot the paralle solution of a large scale rotary wing atme turel dymancs problew. The PETLDP method acts both on the primal and dual form of the interface - exch on a separate portom of the mutrace. We apply this methot in the present work beause there is a substantal volume of published literature demonstrating its high level of pertomance for larse scale engineering problems (see references above). Note, however, that both the ERTLP and the DDDC methods are dosely connected, and we refer the interested reader to the recent work of Mandel ex II7 for an excellent expostion of this con meetion.

The state of -the art in rotary wing structural mode ing involves a variational-aymptotic reduction of the $3 \mathrm{D}$ norlhear elasticity problem into a $2 \mathrm{D}$ hechr crose-section axalysis and a 10 geometrically exact beam malys based on Berdichevsky [18] and ploneered by Hodses and his coworkers [19]. Aeroelastic computations are perfomed on the beam, followed by a recovery of the 30 stress fied. The method is efictent and accurate - except near end redges and discontinuties for whoh a $3 \mathrm{D}$ andiry sis is still needed - as long as the crose-sections are small conpared to the wavelength of delownations along the beam. Modern hingeless and beangles confintions contain $3 \mathrm{D}$ flexible load bearing components near the root that have short aspect ratios and atinot be treated as bewn. Moreover, twement of biakes. depending on their atvanced geomety and material arisotitepy, also recuires contmous improvements based on refuements to the asymptotic ass-section analysis $[20,21,22]$.

A second objectwe of this paper, therefore, is to devetop a 3-D FWM andysis for rotary wing structures that can be used to atalye generic, 3-D, now-bern ike whos as well as anvanced geometry blade shapes. With the emergence of rotoratat CD, physic-based models contaming milions of grid pomes dat carry ou RANS con-

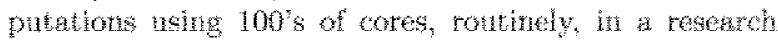
exviromment tor the rotor, and even sot the entire helcopter. Current research is toctsed today on coupling between $\mathrm{CD}$ and relatively simple enginesming-tevel notom struthal thamics. The purpose of the scond objective of this paper, therefore, is to explore the possbitity

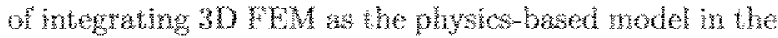
CSD domain.

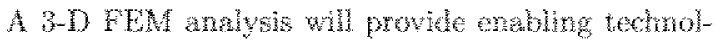


ogy for modeling adwance hingeles and henrimgless rotors. It wil provide enabling technology for calculating the stresses ard string drecty on the critcal load bear ing components near the hub. It will prowde $a$ model that is a true representation of the $3 \mathrm{D}$ structure, con sistent with the high fidty sough in large aule CW computations. Thus, this research is primerly tageted wand large-senle, high-flelty, HPC based conpreherwive rotorchaft simations. However, as a by product, wh wil stll provide a means for extractirg $2 \mathrm{D}$ sectoral propertes for generic structures, with which lower fodelity analysis ean dways be carried ont. There is no question that such a capablity will be powerful. The quetion ts that of an efficient solution procedrese. As in CED, the tremendots capabitines of TPC is also omsioned here to be the key techology driver and ender. The pimary objective of this paper is therefore to addres this key challenge directly.

\section{Scope of Present Work}

A 3 D FEM aratysis tor rotary wing dynamics is developed with emphasis on identifymg the inertial temas that atre uniche to rotors. The 3-D FEM solver is then nsed to implement and analyze a parallel Newton-Kryow solver developed using the FETI DP method of iterative subetruenting. This solver is equpped with a General ized Minimm Resinal (GMPES) update, in addion to its traditional $\mathrm{C} \mathrm{C}$ besed update, to kccomodate the monsymmetric nature of rotaty wing dymancs. However no lomal proot of convergence or condition estimates are derived for this nonsymmetric operator.

Advanced finite element apabilities like locking free elements, herarchical elements, nonlinear constitutive models, composite ply modeling are beyond the seope of this intial work. Grid generation is not part of this endeavor. Smple grids are constucted that are adequate for research purposes. Donain partioning, on the other hard, is a part of this work. Standard graph pertitioners that are readily avalable will not suffice, for reasons described heren. Most isey elements of a comprebensive

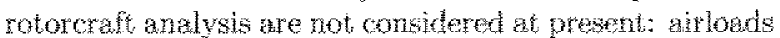
model, trim model, extraction of periodic tyamin, and ruth body dynamics, are all part of tuture work.

The paper is organized as follows. The second sootion describes the formulation of 3 b Fuite Elenent Modelng (FEM) for rotors, followed by prethinary verifotion using thin plate and rotating bean resuls. The third section presents a brief description of the taterave substructuring algorthm and its paralle implementation. The mmerical sealablity of the atgorthm is established in this secton. The fourth section intoduces the Koy components of the $3 \mathrm{D}$ FEM andysis: geometry and grids, partioning wro comer selfow, the hover prototype, and the transient forward fight prototye. The

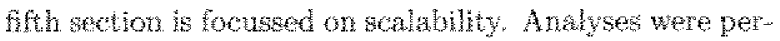
fomed on up to 48 processors $\cdots$ the maximum avalisbe to he anthore prosent prese paper end with the key conchustom of this work, and a summary of the future research directions that ane critical to the success of the endeswour.

\section{D ETNTE ELEMENTS FOR ROTORS}

'the Finte Element formulation is baced on well esbablisher, standsat procetures $[23,24]$. The nom-inear, geometricaly exact implementaton, follows hetemental approach, using Green-Lagratige strain and Stcond Pola-tirchof stres meastres, within a total lagrangian fommaton. The main contribution here is on idontibing the inertial tems that wre uncue to rotorchaft.

\section{Strain energy}

Iet the deformed coordirates of a material point in the blace at aty instart be giver by

$$
\begin{aligned}
& x_{1}=x_{2}^{0}+w_{1}\left(x_{1}^{0}, x_{2}^{0}, x_{2}^{0}\right) \\
& x_{2}=x_{2}^{0}+u_{2}\left(x_{1}^{0}, x_{2}^{0}, x_{3}^{0}\right) \\
& x_{3}=x_{3}^{6}-x_{3}\left(x_{2}^{0}, x_{2}^{0}, x_{3}^{0}\right)
\end{aligned}
$$

where $x^{0}$ and $u, x=1,2, y$ dewote the wheromed coordivates and the 3 D deformation field respectively. The defomation gradient of the point with respect to the undefomed confguration is then $X_{0}$

$$
X_{0}=\left[\begin{array}{lll}
x_{1,1} & x_{1,2} & x_{1,3} \\
x_{2,1} & x_{2,2} & x_{2,3} \\
x_{3,1} & x_{1,2} & x_{3,3}
\end{array}\right] \text { where } x_{i, j}=\frac{\partial x_{i}}{\partial x_{j}^{1}}
$$

The Green-Lagrange stran relates the deformed lergth of line element, $d$, to its onginal length on the undeformed blade, $d 4^{\circ}$, in the following manker

$$
\left.\epsilon_{i j} d x_{i} d x_{j}=(1 / 2)\left[(d h)^{2}-(d)^{6}\right)^{2}\right]
$$

where $(n)^{2}=d x_{i} d x_{i}$ and $\left(d l^{0}\right)^{2}=d x_{i} d x_{i}$. The GrenLagrange strain teneor follows

$$
\epsilon=(1 / 2)(C-1)
$$

whene $O$ is the let Cauchy-Green deformation bensor given by

$$
C=X_{0}^{T} X_{0}
$$

The alements of the Green-Lagrange stran tenser have the well-knowr form

$$
\epsilon_{i j}=\frac{1}{2}\left(\frac{\partial u_{i}}{\partial x_{j}^{0}}+\frac{\partial u_{j}}{\partial x_{i}^{0}}+\frac{\partial u_{k}}{\partial x_{i}^{0}} \frac{\partial u_{k}}{\partial x_{j}^{0}}\right) \quad k=1,2,3
$$

The Fotal Lagrangian fomulation is based on Frant work per unt orighol woluwe. The stress measure that ts anergetically conjugate to Gren Lagrange stran is the second Pola-Kirchoff stress tensor; $\sigma$. That the the stran erergy of the deforned structure car now be cat culated ushe the above strain and stres measures whth integraton over orighal volune. The variation ir stwn energy is then simply

$$
\partial y=\int a d e_{i j} d V
$$


For non-inear analysis, wn incremental procedure is followed. The variatom in strain energy in the current state is expressed in terms of increnental defomations measured from a prewious known state. It must be anderstood that the watation in strin in the current state ss smply the varaton in incrementat stratws. That is,

$$
\delta e_{j}(t+\Delta t)=\partial \Delta e_{3 j}
$$

where 16 is the incremental strin

$$
\epsilon_{i j}(t+\Delta t)=\epsilon_{i j}(t)+\Delta \epsilon_{i j}
$$

The incremental stran is related to the incremental deCommations $\Delta u_{\text {r. }}$. They are defued as follows

$$
\begin{gathered}
x_{i}(t)=x_{i}^{0}+u_{i}(t) \\
x_{i}(t+\Delta t)=x_{i}^{0}+u_{i}(t+\Delta t) \\
\Delta z_{i}=x_{i}(t+\Delta t)-x_{i}(t)=u_{i}(t+\Delta t)-u_{i}(t)
\end{gathered}
$$

Substituton of the strain expression 3 in 6 and use of $u(t+\Delta t)=u_{i}(t)+\Delta u_{i}$ givos

$$
\begin{aligned}
\Delta c_{i j}= & \frac{1}{2}\left(\frac{\partial \Delta u_{i}}{\partial x_{j}^{0}}+\frac{\partial \Delta u_{j}}{\partial x_{i}^{\dagger}}+\frac{\partial u_{k}}{\partial x_{j}^{0}} \frac{\partial \Delta u_{k}}{\partial x_{j}^{0}}+\frac{\partial \Delta u_{k}}{\partial x_{i}^{0}} \frac{\partial u_{k}}{\partial x_{j}^{0}}\right) \\
& +\frac{1}{2} \frac{\partial \Delta u_{k}}{\partial x_{i}^{\dagger}} \frac{\partial \Delta u_{k}}{\partial x_{j}^{0}}=\Delta \varepsilon_{i j}+\Delta \kappa_{i j} \quad k=1,2,3
\end{aligned}
$$

where the linear and non-linear strains are seperately denoted as $E_{i} j$ aret $F_{i j}$. The variations follow

$$
\partial \Delta \epsilon_{i j}=\delta \Delta \epsilon_{i j}+\delta \Delta \kappa_{i j}
$$

where

$$
\begin{aligned}
& \delta \Delta c_{i j}= \\
& \frac{1}{2}\left(\frac{\partial \delta \Delta u_{i}}{\partial x_{j}^{0}}+\frac{\partial \delta \Delta u_{i}}{\partial x_{i}^{0}}+\frac{\partial w_{k}}{\partial x_{i}^{\theta}} \frac{\partial \delta \Delta u_{k}}{\partial x_{j}^{0}}+\frac{\partial \delta \Delta u_{k}}{\partial x_{i}^{0}} \frac{\partial w_{k}}{\partial x_{j}^{0}}\right) \\
& B \Delta w_{1}= \\
& \frac{1}{2}\left(\frac{\partial \Delta u_{k}}{\partial x_{i}^{0}} \frac{\partial \delta \Delta u_{k}}{\partial x_{j}^{0}}+\frac{\partial \delta \Delta u_{i}}{\partial x_{i}^{b}} \frac{\partial \Delta u_{k}}{\partial x_{j}^{0}}\right)
\end{aligned}
$$

Similarly decompose the stress

$$
\sigma_{i, j}(t+\Delta t)=\sigma_{i j}(t)+\Delta \sigma_{i j}
$$

Use 8,9 and 10 in 4 to obtain

$$
\begin{aligned}
\delta V= & \int_{V} \Delta \sigma_{i j} \delta \Delta \varepsilon_{i j} d V+\int_{V} \sigma_{i j}(t) \partial \Delta \sigma_{i j} d V+ \\
& \int_{V} \sigma_{i j}(t) \delta \Delta \gamma_{i j} d V+\int_{V} \Delta \sigma_{i j} \delta \Delta x_{i j} d V
\end{aligned}
$$

The Extegration, ass before, is oner the origind wolume. This expresson is exact for laxge debrmatons, large

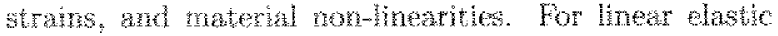

materials, the incremental stress fis related to the incremental hen strain by constitutive retaton of the form

$$
\Delta \sigma_{i j}=D_{i j m n} \Delta \varepsilon_{\text {trit }}
$$

$D$ iman has the geteral form $I^{T} D^{r} L$ with $D^{\prime}$ contaning ihe materal constitution and $I$ the composite ply angle transfomation. The fust tem in 1 then bocrues the standard inear finte ehenent tem. The second term is an incremental tem involung the existing state of stest and theer strins. The third term, whderned, the key term for rotorcraft. It is an incremental tem imwo Ing the exting state of stress and the non-linesr strains. This term froduces the structural couphnge betwen axial and trankverse defomations (torson is not a separate state of motion in $3-\mathrm{D}$ but a function of transverse deformations) in response to inertal effects. It carmes winh it the classical extension-bending and hap-lase structural copplings. The fouth tem is dropped as part of thr

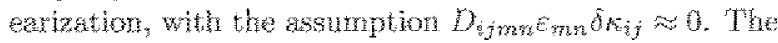
Enal expresion ther becomes

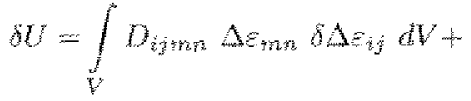

$$
\begin{aligned}
& \int_{V} \sigma_{i j}(i) \delta \Delta \varepsilon_{i j} d V+\int \sigma_{i j}(t) \delta \Delta k_{i, j} d V
\end{aligned}
$$

Iterations are recuired, of comre, primatily for $\sigma_{i j}(t)$ but ako for the Imearizaton. The latter is ustaly insigut icant. For example, for a static solution, given a pre seribed, defomaton independant, nonmental external forcing, the equation of motion takes the form

$$
b U=\delta W_{k}
$$

where $\delta W_{E}$ is the external virtual work. The iterative procedure is then

$$
\begin{aligned}
& \int D_{i, m_{n}} \Delta \varepsilon_{i, m} 3 \Delta \varepsilon_{i j} d V+\int \sigma_{i j}(t) \delta \Delta \kappa_{i j} d V \\
& =\delta W_{E}-\int_{V} \sigma_{y j}(t) \delta \Delta \varepsilon_{j} d V
\end{aligned}
$$

readily recogniged as a Newhon-haphon iteration. If $\sigma_{i j}(t)$ is tpdated only on the right hand side, the procedire is a modifed Newtom iteration For a mor, it must be updated on both sides initidy to obtain the corred non-hned sthese. Thereater, modifed Net-

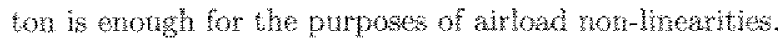

\section{Kinetic energy}

The variation in kinetic evergy or the virtual work by inertal forces is given by

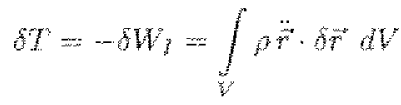

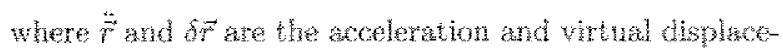
ment of a materal point $P$ on the blabe ratue to an 
inertal frame 1 . Let $P$ lie in a non-inertial frame $B$. The hames $I$ and $B$ are assonited wh comoponding coordinate wax or Easis. At ary instant, frome $B$ has a

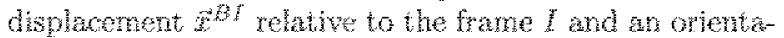

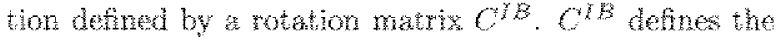
orentation of $I$ relative to $B$, i.e. it rotates the axis from $B$ to $I$. Th the components of $z^{a t}$ expressed in $B$ and $I$ basis are denoted by $x^{B Y / 3}$ and $x^{B T /}$, then

$$
x^{B I / L}=C^{n B} x^{B D / B}
$$

Fecall, that the time dertwative of the rotation matrix is related the thew symmetric angular velocities by

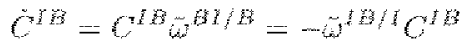

where w $^{B}$ is the angular velocity of $B$ relative to $I$ and measured in $B$, and $w^{n} I /$ is the angular velocty of $I$ relathe to $B$ and measured in $I$. The components of the motion of the point $P$ relative to $I$ and $B$ and expressed in $l$ and $B$ irames satisy

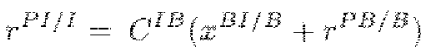

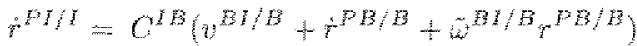

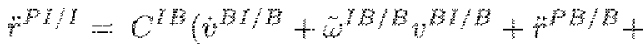

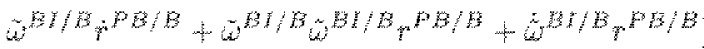

where the frame motions have been expresed in boty

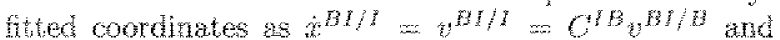

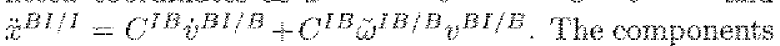
of virtual deptacement are

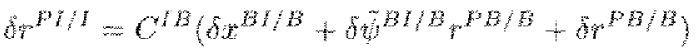

$$
\begin{aligned}
& =C^{I B}\left(\delta x^{B Y / B}-\vec{p}^{P B / B} \delta b^{B M / B}+\phi^{p B / B}\right) \\
& =C^{I B} R^{\gamma} d q
\end{aligned}
$$

where

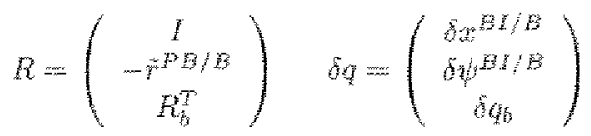

WH/E and W $^{B / E}$ are the rigid body tramiational and motationat states of hrme $B$. The virtual disphement

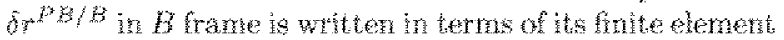
degrees of fredom $\tilde{b} T^{p} B / B=R_{b} \partial q_{b}$. The kinetic energy is then

$$
\partial T=\int\left(\sigma^{P T / Y}\right)^{T} F^{P Y / 1} d V
$$

In generd, Tame $B$ may contain general Texible component. Consider a simple ase for Wustmiton. Let $B$ be the whotomed biade rotating frane, contaning the ex-

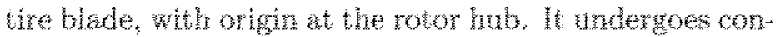
trol angle motions $0,0, \ddot{\theta}$ whth respect to nother rotath

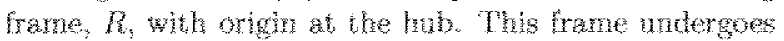

rotalional motions $\Omega, \Omega, \Omega$ with resped to a nor wotathe inertia frame $\vec{I}$ at the hab. $D$ luck no rigid body states

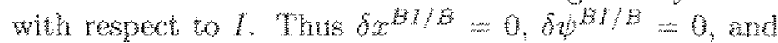

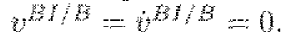

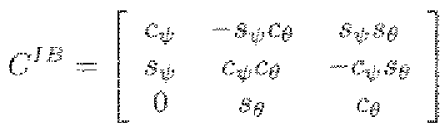

t) - W the blade wimuth ande, $\theta$ is the control angle, and $c_{\theta}=\cos \theta$. atc.

$$
\omega^{B H}=\left(\begin{array}{c}
\dot{\theta} \\
0 \\
0
\end{array}\right) e^{n}+\left(\begin{array}{c}
0 \\
0 \\
\Omega
\end{array}\right) e^{n}=\left(\begin{array}{c}
\dot{\theta} \\
\Omega s_{\theta} \\
\Omega c_{\theta}
\end{array}\right) e^{b}
$$

$e^{B}$ anf $e^{y}$ are the basts vectors in the $B$ and $l$ frame repectively. The ron-zero comporents of $x^{2 x} / \mathrm{t}$ in the kinetic energy expression 16 beche

$$
\begin{aligned}
& F^{P B} B=\left(\begin{array}{l}
\ddot{\vec{v}}_{1} \\
\tilde{u}_{2} \\
\ddot{H}_{B}
\end{array}\right)
\end{aligned}
$$

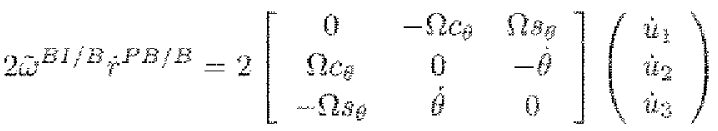

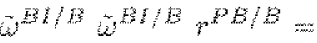

$$
\begin{aligned}
& {\left[\begin{array}{ccc}
-\Omega^{\alpha} & \dot{\theta} s_{\theta} & \dot{\theta} \Omega c_{\theta} \\
\dot{\theta} \Omega \theta_{\theta} & -\Omega^{2} c_{\theta}^{2}-\theta^{2} & \Omega^{2} c_{\theta} s_{\theta} \\
\hat{n c_{\theta}} & \Omega^{2} c_{\theta} s_{\theta} & -\Omega^{2} s_{\theta}^{2}-\theta^{2}
\end{array}\right]\left(\begin{array}{c}
x_{1} \\
x_{2} \\
x_{3}
\end{array}\right)}
\end{aligned}
$$

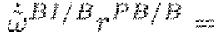

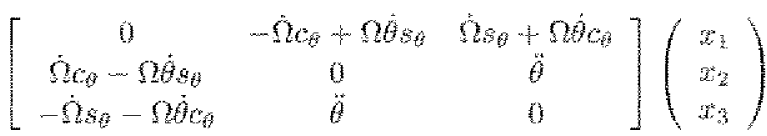

The vitual displacement is simply the variation of the incremente displacements

$$
B r^{P E / B}=C^{H B} \mathrm{bu}
$$

Thu, the kinetic energ 16 takes the following form

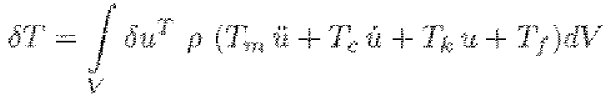

For exampies whithe simplest ascumption of only a col lective, $b=0$, and steaty rotation, $\hat{Q}=0$, we have from 19- 22 the following mass, damping, sthress, and fores 
contrbutens from inerta.

$$
\begin{aligned}
& T_{3 l}=I_{3} \\
& T_{c}=-20\left[\begin{array}{ccc}
0 & c_{\theta} & -\phi_{0} \\
-c_{0} & 0 & 0 \\
s_{\theta} & 0 & 0
\end{array}\right] \\
& T:=-\Omega^{2}\left[\begin{array}{ccc}
1 & 0 & 0 \\
0 & \rho_{\theta}^{2} & -s_{\theta} c_{\theta} \\
0 & -s_{\theta} c_{\theta} & s_{\theta}^{2}
\end{array}\right] \\
& T_{f}=T_{1}\left[x_{1}^{0} x_{2}^{0} x_{2}^{0}\right]^{T}
\end{aligned}
$$

\section{Virtual work by external forces}

A surface lies, always, on one or more of the element

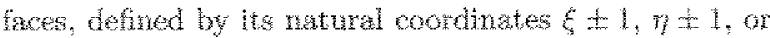
$\zeta \pm 1$ (see following secton). A differential change $d \xi$ in the navaral condinates $(\xi, \eta, \zeta)$ reates the following changes in the geometric courdinates $\left(x_{1}, x_{2}, x_{3}\right)$.

$$
d x_{i}=x_{i, \xi} d \xi=\sum_{k=1}^{N} H_{k, \xi} x_{i}^{k_{i}} \quad i==1,2,3
$$

Simitarly, diflerential charmes dn and $d 6$ create the vextors $x, n$ and $x, b$ in the geonetric coordinates. The ares dEdn, for example, then corresponts to the area of a parallelogram between the two vectors $x_{, z} d \xi$ and $x, k$ dn in the geometric domam, defined by their cross product

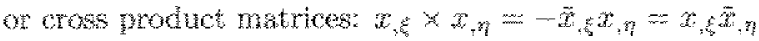

$$
x_{, \xi} \times x_{, \eta}=\left[\begin{array}{l}
x_{2, \xi} x_{4, \eta}-x_{2, \eta} x_{3,5} \\
x_{3,4} x_{1, \eta}-x_{3, r_{3}} x_{1, \xi} \\
x_{1, \xi} x_{2, \eta}-x_{1, \eta} x_{2, \xi}
\end{array}\right]
$$

For example, if nomal pressure $p$ or an elemental face defned by $C=$ constent, produces a virtual work $p d \vec{A} \cdot \vec{A}$,

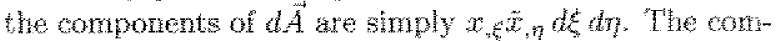
ponents of $d t^{2}$ are the increnental virtual detormations

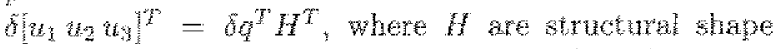
functions (see next section). The virtial work expression is then

$$
\delta W_{E}=\delta q^{T} \int_{A} p H^{T} w_{*} \bar{x}_{,} d \xi d \eta=\delta q^{P} Q
$$

A general stwace stress distribution $\sigma_{S}$ is incomorated in exactly the same manner using $\left(\sigma_{S} \cdot d A\right) \cdot d \vec{u}$.

$$
b W_{E}=\delta q^{T} \int_{A} H^{T} \sigma_{S} x_{s} \tilde{x}_{, 3} d \xi d \eta \cdots \delta q^{T} Q
$$

Becane hud otress are deformation dependant, the area must be wawhed at the deformed conflaration. The deforned configurabon $k$ no known a prion, therefore, itrations are reatred. This is dracused further in the subsection 'Steady Hover Probotype' wher 's-D FFM Rotor Andycis?

\section{Brick Finite Elements}

The analys of bending formated problems mwolving thin strutures using $3-\mathrm{D}$ elenents sufer from severe

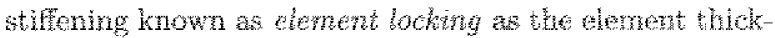
ness tends to zero. A smple but effectve way to prevent lockng is to use higher-order hemeng - as in bhs shdy contaning suffecent number of internal nodes. Dewising eficient lower order lockng tree brick elementw based or reduced-integator or enhanced assumed strain wethods, are beyond the scope of this intural developryent. The primary focus at present ts on accuracy.

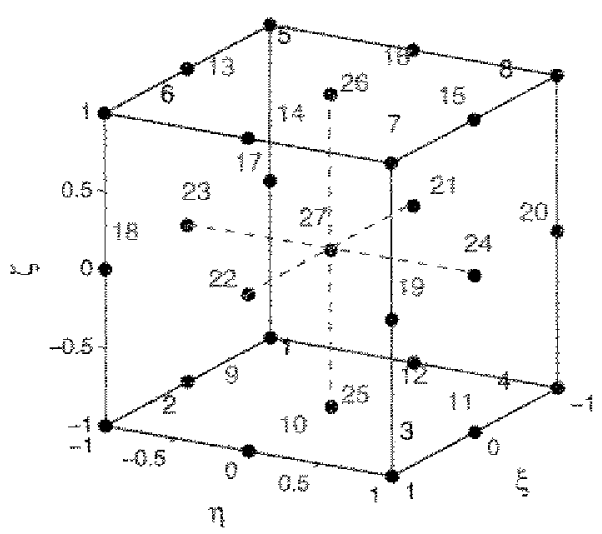

Figure 1: 27-node isoparametric brick element in curvilinear natural coordinates; 64 gauss integram tion points.

Nigure 1 shows a guadratic, lagrangin, isoparametric brick element developed in this study. sists of 8 vertex nodes and 19 intema nodes -. 12 edge nodes, 6 axe nodes, and 1 volume node. Within isoparametric elements. geometry and displacement solution are both interpolated using the same shape functions. The

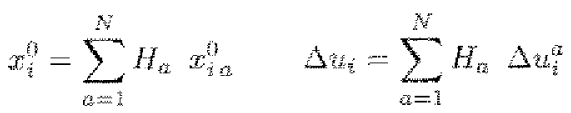

and therefore

$$
x_{i}=\sum_{a=1}^{N} H_{a} \text { isia } \quad u_{i}=\sum_{a=1}^{N} H_{a} h_{i}^{a}
$$

where $a$ is the efenental node point index, $N=27$ here. The shape functions are expressed in elentert faturat coordmates $\xi$ n. and $\zeta$. We consider Latrange polymomiak in explinecton.

$$
H_{a}-H_{a}(\xi, \eta, \xi) \approx L_{l}^{n}(\xi) L_{\bar{J}}^{m}(\eta) L_{K}(\zeta)
$$

In the present formathon $=m=y=2$; and $I, J, K=$

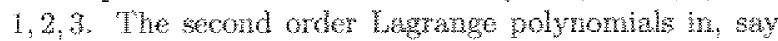
$x$, are $x(x-1) / 2,1-x^{2}$ and $x(x+1) / 2$. For exanple besed on the hoal node ow twing shown in the higue, we have the shape turetion corresponding to node lis as

$H_{n}=L_{2}^{2}(\zeta) L_{3}^{2}(n) L_{3}^{2}(\zeta)=\frac{1}{4} \eta\left(n-\xi^{2}\right)(n+1)(\zeta-1)$ 


$$
\begin{aligned}
& B_{L D}=\left[\begin{array}{cccccc}
H_{1,1} & 0 & 0 & H_{2,1} & \ldots & 0 \\
0 & H_{1,2} & 0 & 0 & \ldots & 0 \\
0 & 0 & H_{2,3} & 0 & \ldots & H_{N, 3} \\
H_{1,3} & H_{1,3} & 0 & H_{2,2} & \ldots & 0 \\
0 & H_{1,3} & H_{1,2} & 0 & \ldots & H_{N, 2} \\
H_{1,3} & 0 & H_{1,1} & H_{2,3} & \ldots & H_{N, 1}
\end{array}\right]
\end{aligned}
$$

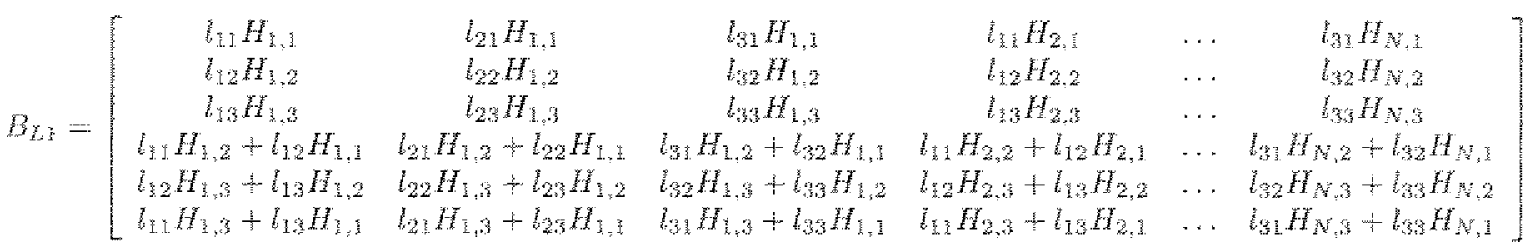

The strains require the derivatives of the shape functions with respect to geometric coodinates

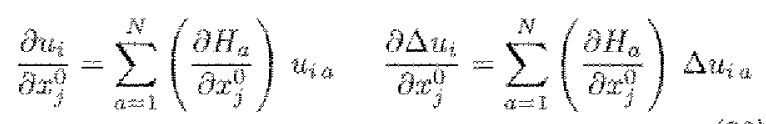

These are calculated from the derivatwes with respect to natural coordinates as follows

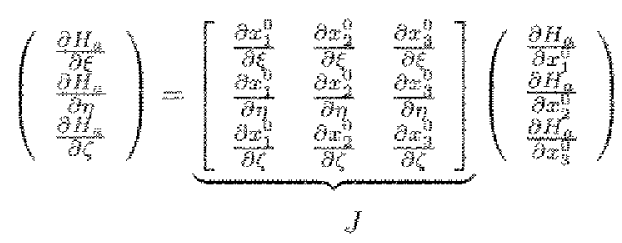

The evaluation of the Jacobian, $J$, is atraight forwat using the deriwatives of the shape functions with respect to element ratural coordinate axes and the location of the nodal points (i.e. the grid points).

$J=\left[\begin{array}{cccc}H_{1, \xi} & H_{2, \xi} & \ldots & H_{N, \xi} \\ H_{1, \eta} & H_{2, \eta} & \ldots & H_{N, \eta} \\ H_{1, \zeta} & H_{2, \zeta} & \ldots & H_{N, \zeta}\end{array}\right]\left[\begin{array}{ccc}x_{11}^{0} & x_{3,}^{0} & x_{3,}^{0} \\ x_{12}^{0} & x_{22}^{0} & x_{32}^{0} \\ \ldots & \ldots & \ldots \\ \ldots & \ldots & \ldots \\ \ldots & \ldots & \ldots \\ x_{1 N}^{0} & x_{2 N}^{0} & x_{3 N}^{0}\end{array}\right]$

The requred detivatives are then

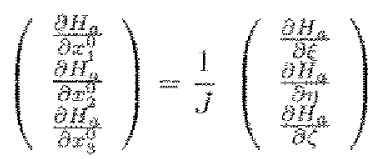

Hencorom the abowe derivative are dencted as

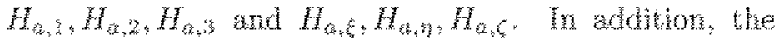
frot quantivy in 32 is denoted by $l_{i j}$, s.e.

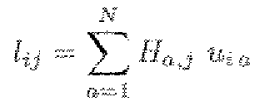

From the linerat stmin $\Delta z_{i j}$ as defined in 7 , the straindisplacement relation now takes the following form

$$
\Delta \hat{\varepsilon}=\left(B_{l 0}+B_{l-1}\right) \Delta q
$$

where

$$
\begin{aligned}
& \Delta \varepsilon^{T}=\Delta\left[\begin{array}{llllll}
\varepsilon_{11} & \varepsilon_{22} & \varepsilon_{13} & 2 \varepsilon_{12} & 2 \varepsilon_{23} & 2 \varepsilon_{13}
\end{array}\right] \\
& \Delta q^{T^{*}}=\left[\begin{array}{lllll}
u_{1} u_{21} u_{31} & u_{12} u_{Z_{2}} u_{12} & \ldots & u_{1 N} u_{2 N} u_{3 N}
\end{array}\right]
\end{aligned}
$$

and the expressions for $b_{h \text { fl }}$ and $b_{L 2}$ are given wowe. The finst term in the stran wergy 12 now becomes

$$
B \Delta q^{T}\left(\int_{V}\left(B_{t a}+B_{L V}\right)^{T} D\left(B_{t a}+B_{b i}\right) d V\right) \Delta q
$$

The cecond term is trexted is the same wamer to obtan

$$
\delta \Delta q^{T}\left(\int\left(B_{L b}+B_{L 1}\right)^{T} \partial(t) d V\right) \Delta q
$$

where $\theta(t)=\left[\begin{array}{llllll}\sigma_{11} & \sigma_{22} & \sigma_{53} & \sigma_{12} & \sigma_{23} & \sigma_{23}{ }^{\prime}\end{array}\right]^{2}$. Now consider the nom-inear incremental strain $\Delta$ ras as defined in 7 .

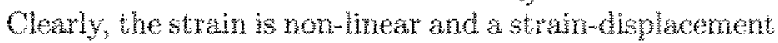
relationship cantwot be fond. However ir has a gadratice form, and hence an be re-atranged at

$$
\delta \Delta q^{T}\left(\int_{V} B_{N L}^{T} \sigma_{i, j}(t) \tilde{B}_{N L} d V\right) \Delta q
$$

whin the matrices having spechal forms

$$
\begin{gathered}
\sigma(b)=\left[\begin{array}{ccc}
\sigma(t) & 0 & 0 \\
0 & \sigma(t) & 0 \\
0 & 0 & \sigma(t)
\end{array}\right] ; \quad 0=\left[\begin{array}{lll}
0 & 0 & 0 \\
0 & 0 & 0 \\
0 & 0 & 0
\end{array}\right] \\
B_{N Z L}=\left[\begin{array}{ccc}
B_{N L} & 0 & 0 \\
0 & B_{N L} & 0 \\
0 & 0 & B_{N L}
\end{array}\right] ; \quad 0=\left[\begin{array}{l}
0 \\
0 \\
0
\end{array}\right]
\end{gathered}
$$




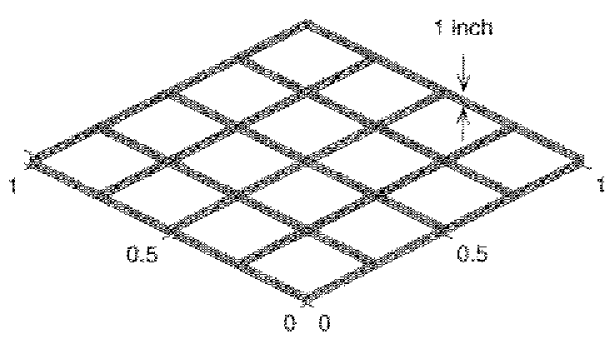

Figure 2: A cantilevered plate using $(4,4,4)$ brick element grid

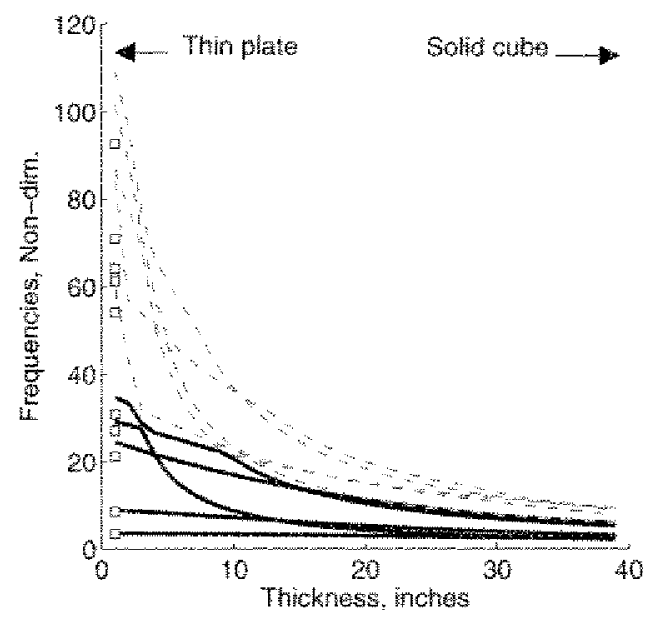

Figure 3: Verification of brick elements; Natural frequencies of a $(4,4,4)$ solid block approaching Kirchoif plate frequencies (symbols) with reduced thickness

$$
B_{N L}=\left[\begin{array}{cccccccc}
H_{2,3} & 0 & 0 & H_{2,3} & 0 & 0 & \ldots & H_{N, 1} \\
H_{1,3} & 0 & 0 & H_{2,2} & 0 & 0 & \ldots & H_{N, 2} \\
H_{1,3} & 0 & 0 & H_{2,3} & 0 & 0 & \ldots & H_{N, 3}
\end{array}\right]
$$

The volume iniegrations are pertormed using 4 geuss points along each natural coordinate axes, a total of 64 integraton points. Note that

$$
d V=\operatorname{det}(J) d \xi d \eta d \xi
$$

\begin{tabular}{|c|c|c|c|}
\hline $\begin{array}{c}\text { Mode } \\
\text { munber }\end{array}$ & $\begin{array}{c}4 \times 4 \times 4 \\
\text { Bricks }\end{array}$ & $\begin{array}{c}8 \times 8 \times 4 \\
\text { Bricks }\end{array}$ & $\begin{array}{c}\text { Kirchhof } \\
\text { Plate }\end{array}$ \\
\hline 1 & 3.55 & 3.50 & 3.47 \\
\hline 2 & 8.68 & 8.53 & 8.51 \\
\hline 3 & 22.93 & 21.58 & 21.29 \\
\hline 4 & 28.16 & 27.29 & 27.19 \\
\hline 5 & 32.84 & 31.19 & 50.96 \\
\hline 6 & 56.78 & 54.31 & 54.13 \\
\hline 7 & 71.19 & 63.00 & 61.29 \\
\hline 8 & 74.75 & 64.96 & 64.16 \\
\hline 9 & 83.68 & 72.50 & 70.98 \\
\hline
\end{tabular}

Thble 1: Plate frequencies using $3 \mathrm{D}$ FEM: nondimensionalized w.r.t. $\sqrt{D / p t a}$, $a$ plate dimension, $t$ t thickness, $\rho$ densty, $D=k^{3} / 12\left(1-v^{2}\right)$ E: Young"s Modulus and $2 /$ Polsson's ratio

\section{VERTFICATTON of ID FEM}

A prehminary verifeat ton of the $3 \mathrm{D}$ DEM model is carred out by reprowueing non-rotating thin plate fre quencies, and rotating slender bean frechencies. The fomer werifes the locknt free behavor. The later verfes the non-linear implenentation.

\begin{tabular}{|c|c|c|}
\hline section grid & Torsion 1 & Torsion 2 \\
\hline $1 \times 1$ & 1.710 & 5.132 \\
\hline $2 \times 2$ & 1.586 & 4.758 \\
\hline $3 \times 3$ & 1.577 & 4.733 \\
\hline $4 \times 4$ & 1.576 & 4.728 \\
\hline $5 \times 5$ & 1.575 & 4.726 \\
\hline
\end{tabular}

Table 2: Beam torsion frequencies vs. crosssection grid refinement; 8 spanwise elements; nondimensionalized w.r.t. $\sqrt{G J / / h^{2}} ; \mathrm{EB}$ val les are 1.571 and 4.712 ; Beam dimensions are $L \times c \times c=100 \%$

\begin{tabular}{|c|c|c|c|}
\hline Thickness & 8 & 16 & 20 \\
& $3 \times 3$ & $3 \times 8$ & $3 \times 3$ \\
\hline $\mathrm{c}$ & 4.733 & 4.726 & 4.725 \\
\hline $\mathrm{c} / 2$ & 4.737 & 4.746 & 4.742 \\
\hline$c / 4$ & 4.824 & 4.794 & 4.781 \\
\hline$c / 8$ & 4.886 & 4.839 & 4.824 \\
\hline
\end{tabular}

Table 3: Second torsion frequency vs. spanwise grid refinement; $3 \times 3$ cross-section: nondimensionalized w.r.t. $\sqrt{G J / L L^{2}}$, EB values are 1.57 and 4.712

\section{Thin Plate Frequencies}

The lockng free behavior of the brick elements: in shear, is verifed by reproducting Kirchof plate frecuendes for a thin plate, using $2(1,4,4)$ brick mesh Fig. 3. The plate frecuenctes an obtained from converged $2 \mathrm{D}$ rectargular plate finte tements $(20,20\}$ and are ral dated exsly with documented dassical solutons. The diserepancy at the higher moles are resolved using a frep mesh converged solution, see Table . The residun di ferencos are due to stear, not present in the Kirchhol solution, but present in the brick solution. 


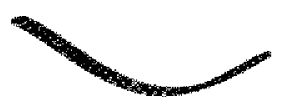

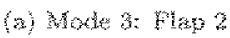

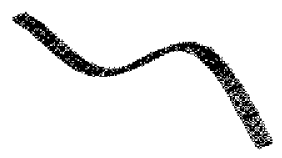

(c) Mode 5 : $\operatorname{man} 3$
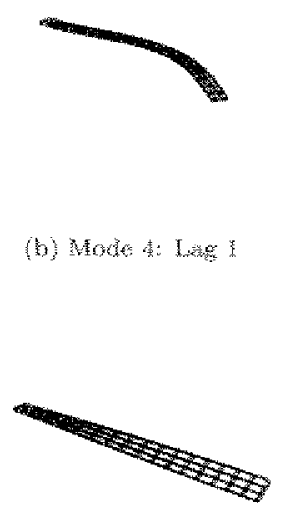

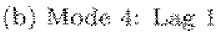

(d) Note 6: Tonen

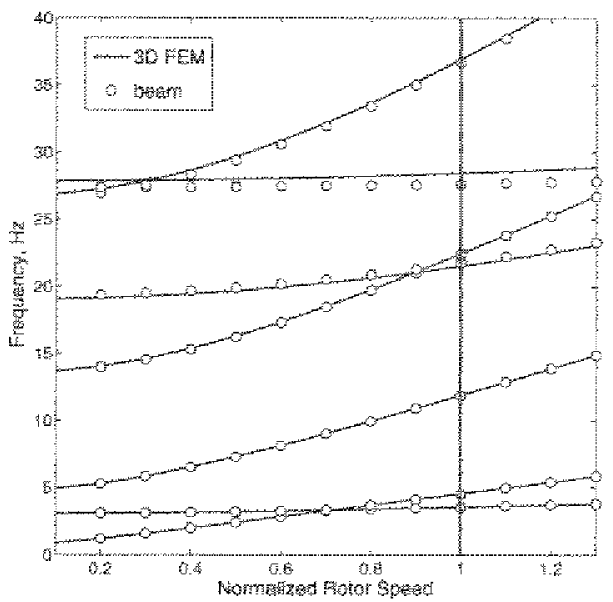

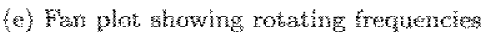

Figure 4: Rotating frequencies and mode shapes of an uniform hingeless blade of aspect ratio 15 , thickness $25 \%$ chord, and rectangular cross-section; 3-D bricks vs $1-D$ beam; $16 \times 3 \times 3$ grid

\begin{tabular}{|c|c|c|}
\hline $\begin{array}{c}\text { Aspect } \\
\text { Ratio }\end{array}$ & Tonsion & Torston 2 \\
\hline 100 & 1.598 & 4.794 \\
\hline 40 & 1.590 & 4.799 \\
\hline 20 & 1.603 & 4.813 \\
\hline 15 & 1.606 & 4.826 \\
\hline 10 & 1.615 & 4.860 \\
\hline 8 & 1.622 & 4.800 \\
\hline 6 & 1.635 & 4.919 \\
\hline 5 & 1.645 & 4.991 \\
\hline 4 & 1.662 & 5.064 \\
\hline 3 & 1.794 & 5.478 \\
\hline
\end{tabular}

Table 4: Torsion frequencies ws. aspect ratio: $16 \times$ $3 \times 3$ grid; nondimensionalized w.r.t. $\sqrt{G I / I / h^{2}}$; EB walue renain 1.571 and 4.712 for all aspect patios.

\section{Slender Beam Frequencies}

Next, the 30 element is verthed ving a slender of unifom geometry that behaves as a bearn over a reason. ably large wariation min thickess and aspect ratio. The bending freguenctes are exsy to re prodwo, torsion in general requires greater resolution. An unform almder beam of aspect ratio 100 and square cros-sector, i.e. the dirrensions are $100 c c$, wh $c$, in length, width, and thichnes, is considered. The torsion frequenctes converge towerds Euler-Bernoull numbers wht two to three cros-

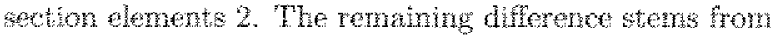
spamwsse reastiticn.

The effect of ganwise resolution is shom in the first row of Thble 3 , stating mom $8 \times 3 \times 3 \mathrm{grd}$ as the buseIrine. Spanwise resolution beomes mone importent as

\begin{tabular}{|c|c|c|c|}
\hline $\begin{array}{l}\text { Mode } \\
\text { no. }\end{array}$ & $\begin{array}{c}\text { Meam reas. } \\
\text { (/req) }\end{array}$ & $\begin{array}{c}\text { 3- 1) fregs } \\
(\mathrm{hev})\end{array}$ & $\begin{array}{l}\text { Mode } \\
\text { tye }\end{array}$ \\
\hline 1 & 0.826 & 0.821 & Lax \\
\hline 2 & 1.059 & 1.056 & Feap I \\
\hline 3 & 2.768 & 2.760 & "lap 2 \\
\hline 4 & $0.0 \% 8$ & 8.006 & $\log 2$ \\
\hline 5 & 5.21 .1 & 5.223 & Ftap 3 \\
\hline 6 & 6.431 & 6.62 & Torsion \\
\hline 7 & 8.542 & 8.507 & That \\
\hline
\end{tabular}

Table 5: Rotating frequencies for a softumplane hingeless rotor; $16 \times 3 \times 3$ grid in 3 D; L: Lag, F: Flap, T: Torsion

the beam thiches sodued. This is shown in the sul secuent rows and columns of Thabe 3 . The rows thow the vation of torsion freduexy wh a progressivey thinner beam. The columms show the efect of spanwhe? refinement for ow thichese There is increased dever thon from Eulet-Berromm walues as the thickness reduces. With the thichess fired at $c / 4$ and the grid at $16 \times 3 \times 3$. the aspect ratio of the beam is now progressively refuced. Table 4 show that from 100 te 20 the requences reman relatively constant. At aspect ratio 5 there is stil ony an error of $5-6 \%$. This devedton is expected from the physes of the problem and is not an ertor in the tom commlation.

Considet the conguration with length 20 , widh

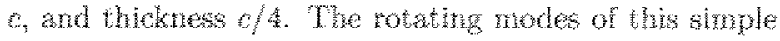
becm structure we shown in fig, dhe requancy plot.

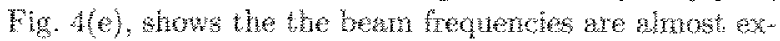
axtly feprowiced by $3 \mathrm{DCH}$ - ant the small gid size of $16 \times 3 \times 3$ is a 
that this serves as a verification of the nowlinear for mulation. The torsion frecuency shows an erwor of $5 \%$ consistent whth the deviation from Enler-Bemoull the puencies in the non-rotating case for the level of grid refmenent. For this structure, the torton frequery is relatwey high, and ocurs ony as the stuh rode. The rotating frequences at $\Omega=27 \mathrm{tad} / \mathrm{s}$ are given in table 5 , both for a bean and the 3-D analysis.

\section{TTENATIVE SUBSTRUCTURING USING PARALLEL KRYLOV SOLVER.}

A paralle Newton Krylow solver is developed to provide an efficient arict scakble $3-0$ FEV solution.

Largescale structural dynamic problems ane solved most efferenty uning the method of substructures. Sub atpucturing involves partitining a stancture into non overlapping subumains. It is the most accurate method, becanse each subdomain can have its own interna solver depending on its local condition number. Amost always, a direct factoriation is preferred $A$ real structure contans signifcant heterogenesties - thin and slender geometres, plate and shells by bihamonic. PDEs, 3D bricks with high bandwidth ( 1000 ), non-linear materias, and constraint forcs - factors that routmely give wise to condition numbers of $10^{8}-10^{\mathrm{m}}$

Modern methods of teratve subtructuring pro vides a donain-decompositon hased preconditoned iterative solver for the interace problem. The interface problem nexd not be of primal type, but can also be of cual type. A primal problem consists of variables that whe a subset of the original wanowns, eg. the displace ments at the interfoce. A dual problem consists of vari ables that ate not subset of the origind unknowm but whose equatity must still be gauranteed, e.g. the reaction Forces at the interface. Dewending on the problem dual variables differ bending problens will involve transwerse shears and moments, whereas a phane stress or stratn problem will onvolve only in-plane stresses. Regardless of ype, whether primal or dual, all finte element interface descriptions are precisely the discrete eruivalents of the Poincares Steklow operator.

The knterface has attractive spetral properties as a result of which it is more anenable to iterative solve. In perticular, mulke the substmetures themsetves, whe condition number of the interiace problem grows at a Eate that is ar order slower compared to the original problem, $a, g$, by $0\left(h^{-1}\right)$ for second order and by $0\left(h^{-3}\right)$ for fourth order PDEs. However, it also grows, necessarly, at o $\left(H^{-2}\right)$ where $H$ is the sudomatr size. For a second-

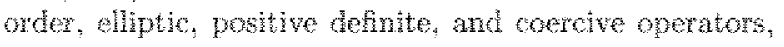
the urecise number for wniform finte elsment neshing giver by [25]

$$
\kappa(s) \leq C \frac{H}{h H_{\gamma}^{2}}
$$

where $H$ is the maximum and $H_{m}$ is the minimuth subdoman trameter. The nain objective of iterative snbstructuring is to provide precondionems shen that the preconditioned interface problem has a condition number independant of both $h$ and $H$. Such a preconditioner is an optimal preconditioner. At the same time, it must be onstructed in pardlel, subdomant by subdmain. requating only communicston betwen subdomains tut no other serat operation - otherwise the primary purpose of iterative abstructuring is deleated.

The dependance on $0\left(\mathrm{H}_{\text {+⿱⺈ }}^{-2}\right)$ cannot be prevented without a coarse grid solver - communtcation only be

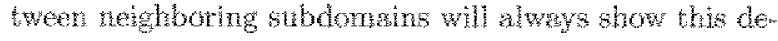
pendance. Thus, a coarse problen t.e. a general mecha nign to propagate local infornation globally, is a central requimente of any scaleble solwer.

The general bulding blacks of a precondthoned Krylow solver (for solving $M^{-5} A x=M^{-1} b$ are: (1) resicual calutation $r=b-A x$, (2) prexouthoning $M^{\sim} r$ and, (3) a matrix-vector mulphicaton Ax. Am terative substructuting aloonthm provides these buhding blocks in a subdomain independant, parale manrer. Once the buldng block are provided, constucting a Krylov solver is trivial. Wnhke the $\mathrm{CO}$ update, the GMRES update, however, poses th own parahelizaton isstest due to the Arroldi procedure.

\section{The FETI-DP Algorithm}

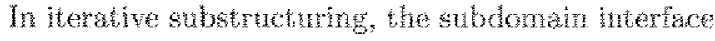
nodes are first separated into vertex, edge and face nodes. The vertex nodes and a subset of edge nodes are ther

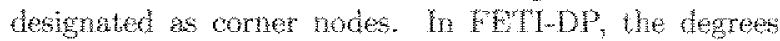
of hedom (DOFs) assoctated with the comer nodes are formtlated as a primel interface. The Dope assochated with the rest are fommated as a cual intertace. The corner nodes form a coarse problen that propugates low cal stbdoman information globaly. Hexsuse the number of DOFs associated with a corner depend on the order of the problem, ie. 3 DOFs for 2 nd order brick FEM or 6 DOFs for 4 th order plate or shell elements, it attomatically renders the coarse mesh approprately tenser wh increase in orter. The FWII DP nethod and its imple mentation in this strety is entirely based on the work of Refs. $[15,16]$. A detaled exposition of our mplementa. tion is not provided here. A bref destiption is proveded below summatining its key aspects.

For a given subdomain, if its nodes are reordered with interna nodes $I^{s}$ trest, fllowed by interface nodes Ts: and then comer nodes $P$ (for a selecton of coner nodes in 3-D, see next sechon), then a subdoman matrix. cay the stifness natrix, takes the following form

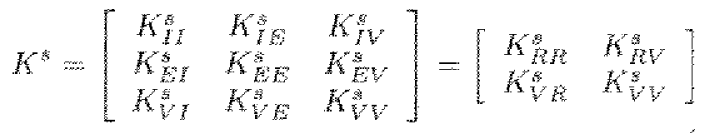

where the intemal snd whe notes are denoted together as $h^{s}$ nodes. The subdoman forche, $f^{s}$, she whnown, $w^{*}$, are comespondingly

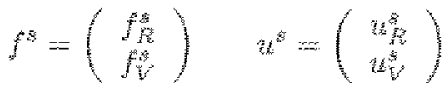


where

$$
u_{R}^{s}=\left(\begin{array}{c}
u_{f}^{s} \\
u_{E Z}^{s}
\end{array}\right) \quad f_{R}^{\hat{B}}=\left(\begin{array}{c}
f_{i}^{s} \\
f_{E}^{p}
\end{array}\right)
$$

Two brolean restrictions are defned tor each subdomain.

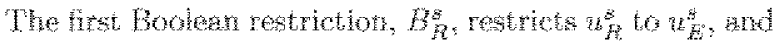
assigne $a+1$ on -1 sign such that equally of the interface degrees of tredon are ganranted upon convergenee.

$$
\sum_{s} B_{R}^{s} u_{R}^{s}=0
$$

The summation sign denotes asembly over subdonains. The second Boolewn restretion, $B_{C}^{*}$, restrids the glowal crmer nodes to subdomain comers. Note that, for a we ordered subdomain, the first restriction, $B_{R}^{*}$ has the form and sige

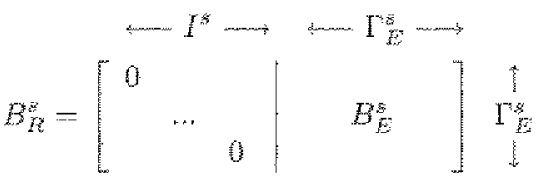

where $B_{z}^{c}$ is a diagonal matrix whl ertries +1 or -1 . The dual primal procedure computes a set of dual vari ables (awhinary variables that ate not part of whe originat problem which on convergence allows the recovery of the subhoman internal and edge nodes as

$$
K_{R}^{3} u_{R}^{s}=f_{R}^{k}-B_{R}^{r} \lambda^{s}
$$

and the global corner nodes as

$$
K_{W}^{*} u_{V}^{g}=F_{W}^{T} \lambda+f_{V}^{*}
$$

The comer problem, which propegates error globally, is n coarse grid problem that is ako constructed subdoman by subdomain. Formally,

$$
\begin{aligned}
& K_{V V}^{*}=\sum_{s} B_{V}^{s}\left[K_{V V}^{s}-K_{P V}^{s} K_{R V^{-1}}^{s} K_{R V}^{s}\right] B_{V}^{a} \\
& F_{F V}^{T} \lambda=\sum B_{V}^{R}\left[-K_{R V}^{s}{ }^{T} K_{R R}^{s}{ }^{-1} B_{R}^{s}{ }^{T}\right] \lambda^{s} \\
& f_{V}^{*}=\sum_{s} B_{V}^{s}\left[K_{R V}^{s} K_{R R}^{s}{ }^{-1} f_{R}^{s}-f_{V}^{s}\right]
\end{aligned}
$$

The solve, however, is carred out in every subdomain. Thus, before the interface iterutions begn, the subdomin conmbutions to the left hard side of the oomer problem are constructed and actorized in every subdo man, and globaly communicated. Theredter, during the mtertace Krylow iteratons, the coarse probien anve is only a repoated right hand side solve.

The bulding biock of the Krylop theration: restual calculaton, preconditioning and matrix-actor mutiolcation procedure are brefly stated below.

\section{Residue calculation}

The frst part of the residual $T_{1}$ is obvioudy

$$
\begin{aligned}
& r_{f}=\sum_{s} B_{k}^{*} w_{R}^{B}
\end{aligned}
$$

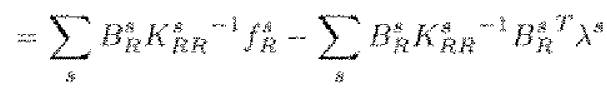

The second part of the residual $r_{z}$ is obtaned after the conse solve

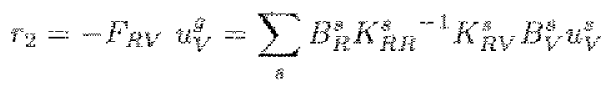

The residual then $r=r_{2}+r_{2}$. Note that the rexd wal culculation is based on subdomain Newnamin solves. Thereter, the subdoman partitonimg, and contre node selector must enswre mull koutels.

\section{Proconditioner}

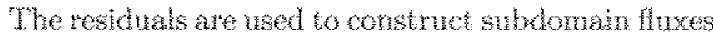

$$
\eta^{\mathrm{s}}=K_{E Z}^{s} w^{s}+K_{E E}^{*} B_{E}^{s} r_{E}^{s}
$$

with we obtaned ustng subdoman Drichlet solves

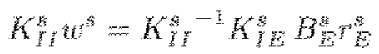

from which the preconeltioned residual follows

$$
M^{-1} r=\sum_{s} B_{E}^{k} \eta^{s}
$$

Lxpandirg the above expresions, we hre, formaly

$$
M^{-1}=\sum_{s} B_{R}^{s}\left[\begin{array}{cc}
0 & 0 \\
0 & S_{E B}^{s}
\end{array}\right] B_{F}^{s}
$$

where $5^{5}$ we the subdoman Schu complement matrices. Anore efficient preconditoner (but not optina) is obtaned by stipping the Drichlet solve about ant celculating the muxes diredly as

$$
\eta_{s}=K_{E E}^{s} B_{Y F}^{f_{F}^{*}}
$$

This leads formally to

$$
M^{-1}=\sum_{s} B_{F}^{g}\left[\begin{array}{cc}
0 & 0 \\
0 & K_{B E}
\end{array}\right] B_{R}^{Y}
$$

The subatman Schnt complement matrices have been approwimated here by their leading tems. The two precondinoners above are termed the Drrichlet and lumpd preconditioners. All results shown later in this paper use the Drichlet preconditonet, even though for $30 \mathrm{D}$ brich problems the lumped preonditioners are lnown to be faster.

\section{Matrix-vector multiplication}

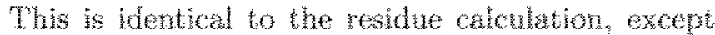

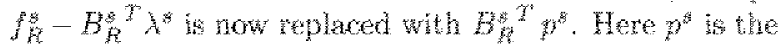
stbdomait restrictor of the vector to the maltipled.

\section{Numerical scalability}

For a symmetric and coerive ellptic operator the conditon number of the preconditioned $\mathrm{FETH}$-10p therhace problem can be shown to grow as

$$
n=O\left(1+\log \frac{H}{h}\right)^{n} ; \quad \text { where } n \leq 3
$$




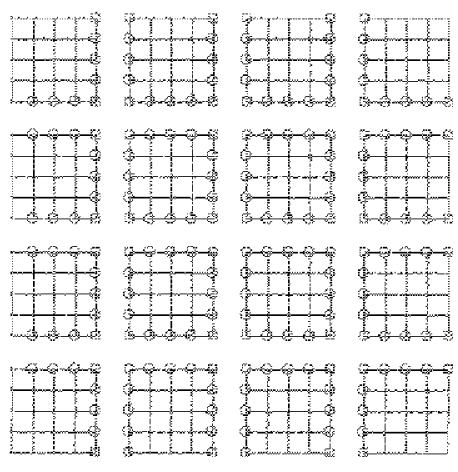

Thure 5: $4 \times 4$ plate partitioning; 16 elements in each partition. Interface, corner, and boundary nodes shown in red, blue, and green respectively.

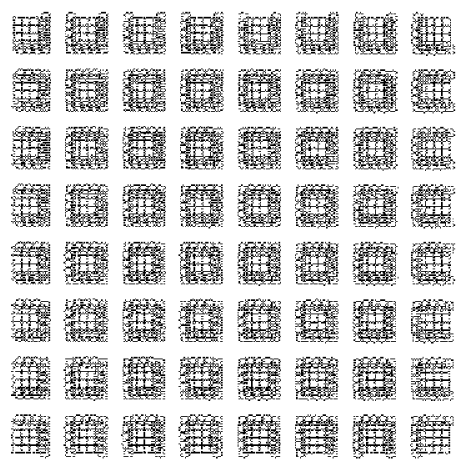

Figure 6: A $16 \times 16$ plate partitioning; 16 elements in each partition.

- That is, if the subdomains have size $M$, and the finte chement wesh hes size $h$, then the condition number of the interface grows only as $t / h$. The condition num ber deterwines the iteration contut rechired for conver. gence. For optimal sealability algorithm, the itation count does not grow with the rumber of subdomuins as long as the mesh withly each subdomain is refned to keet $H / h$ constent. Thus, a bigger problem with additonal subdowains require the sane iteration compt as a smaller problem as long as both contain the same mesh reolution.

The opturality of the algorthm is verifed on a plate berding problem. Plate bending, like beam bending:

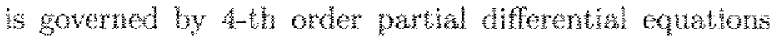
and is contidered challenge for iterative solvers becanse their condhon number grow at a tate $0\left(h^{-4}\right)$. Thbles 6

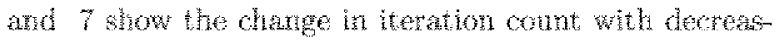
ne values of $h$ and $H$ reptetively. The itetabion cout increases with increase in $H / h$ and decreases whth decrevase in $H / h$. However, if $H / h$ is hel fxed, Thate 8 shows, as dested, the iteraton count remans polatively constant. Thus, the two plate problems shown in $17 \mathrm{gss}$. 5 and 6 converge at the same nate - even thotgh the later is fom thes as big as the former.

\begin{tabular}{|c|c|c|c|c|}
\hline$i_{k}$ & $n_{s}$ & $n_{\text {edef }}$ & $\begin{array}{c}\text { FETHP } \\
\mathrm{CQ}^{3}\end{array}$ & $\begin{array}{r}\text { FEM-DH } \\
\text { CMRES }\end{array}$ \\
\hline $1 / 8$ & 16 & 216 & 18 & 21 \\
\hline $1 / 12$ & 16 & 468 & 23 & 26 \\
\hline $1 / 16$ & 16 & 816 & 26 & 31 \\
\hline $1 / 20$ & 16 & 1260 & 29 & 30 \\
\hline $1 / 24$ & 16 & 1800 & 32 & 39 \\
\hline $1 / 32$ & 16 & 3100 & 37 & ${ }_{12} 6$ \\
\hline
\end{tabular}

Table 6 : Namber of substructures fxed $n_{3}=16(4 x$ (1) mesh partition). Iteration count $v s$. increase in problem size.

\begin{tabular}{|ccccc|}
\hline$\pi$ & $n_{s}$ & $n_{\text {rof }}$ & $\begin{array}{c}\text { FEMTDP } \\
\text { CG }\end{array}$ & $\begin{array}{c}\text { PETIDP } \\
\text { GMRES }\end{array}$ \\
\hline $1 / 3$ & 9 & 1260 & 31 & 46 \\
$1 / 4$ & 16 & 1260 & 32 & 41 \\
$1 / 6$ & 36 & 1260 & 29 & 33 \\
$1 / 8$ & 64 & 1260 & 25 & 29 \\
$1 / 12$ & 114 & 1260 & 21 & 23 \\
\hline
\end{tabular}

Table $7:$ Problem size fixed DoFs $=1260(h=1 / 24$ mesh). Itexation count $v$ s. incrase in number of substructures.

\begin{tabular}{|ccccc|}
\hline$h_{s}$ & $n_{s}$ & $n_{h o}$ & $\begin{array}{c}\text { RETL-DP } \\
\text { CG }\end{array}$ & $\begin{array}{c}\text { FETLDP } \\
\text { GMRES }\end{array}$ \\
\hline $1 / 12$ & 9 & 468 & 23 & 29 \\
$1 / 16$ & 16 & 816 & 26 & 31 \\
$1 / 20$ & 25 & 1260 & 28 & 32 \\
$1 / 24$ & 36 & 1800 & 29 & 33 \\
$1 / 28$ & 49 & 2436 & 30 & 34 \\
$1 / 32$ & $6 \%$ & 3168 & 30 & 34 \\
\hline
\end{tabular}

Table 8: Problem size per substructure fled $I / h=4$ (16 elements per substructure). Iteration count vs. increase in problem size.

\section{Parallel Implementation of $\mathrm{CG}$}

A standard Compugate Gradient ( $\mathrm{PCC})$ update is as show below. The main lyilding block that are constructed timg the paralde WEILDP proodure are high lighted in bold.

$$
\begin{aligned}
& \lambda_{0}=0 ; \quad r_{0}=d-F \lambda_{0} \\
& \text { for } f=1,2, \ldots \\
& z_{\text {葆-1 }}=\mathbf{M}^{-1} \mathbf{r}_{\mathrm{k}-1}
\end{aligned}
$$

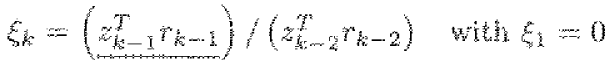

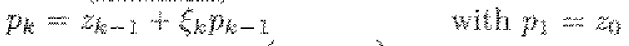

$$
\begin{aligned}
& \gamma_{k}=\left(z_{k-1}^{T}{ }^{T}-1\right) /\left(p_{k}^{T} \mathbf{F} \mathbf{p}_{k}\right) \\
& \lambda_{k}=\lambda_{k-1}+\gamma_{k} \hat{z}_{k} \\
& r_{k}=r_{k-1}-\gamma_{k} p p_{p}
\end{aligned}
$$


end

In addition to the communication requirements for the FEll-DP, the CG update regures procesor sychronuation poing of its own. These are points beyond which catcethations cannot proeed anles all processors teach that point. All vector inner prodtets ate suchronizaton points. The two synchromination points are underIned above. An additionel syndronitaton point se re gured to calculate the norm of the predonditioned rean.

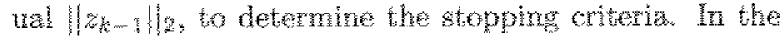
case of $\mathrm{CG}$, the total number of potres can be reduced to one, using advancel torm estruton techntage $[26,27]$, This refinement has not been ineluded at present, but it is testred when thousants of distributed memory nodes are eventually used.

\section{Parallel Implementation of GMRES}

A GMRES update require an Arnoldi procedure and a solution of a least-scuare problen. A Reorthogona ized Classical Gran-Senimdt Amold procedure is imple mented in this stuty, based on the seminal work of Daniel

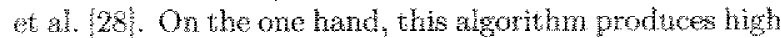
levels of orthogonalization (down to machite prection) and is sugerior to Modifed Cram-Schmidt fo9. On the othe hand, it remedies the macoptsble communication costs of the latier (explained below). Note that, a Classical Gram Schiradt (1e, whitou Reorthogonatiation) is numericaly unstable and ts not usec in practice.

Recall, given an mital extmate $x_{f}$ and residual $r_{0}=b-A x_{0}$, every mih CMLES iterate for the som itution of $A x=b$ is given by $x_{w_{i}}=x_{0}+K$ where $K$ lies in the Krylow subspace of dmension m associated with $A$ and $r_{0}, K_{m}\left(A, r_{0}\right)=\operatorname{span}\left(r_{0}, A r_{0}, \ldots, A^{n-1} r_{0}\right)$, and minimizes the norm $|b-A x|_{2}$.

The Amold procedure in dimension $m$ constructs an or bonormal basts $V_{m}=\left\{v_{1}, v_{2}, \ldots, v_{m}\right\}$ of the Krylow stuspace $K_{3 n}\left(A, F_{0}\right)$. The procedure atso generates a ma trix $\bar{I}_{m}$ of size $(m+1) \times m$ the ton $m \times m$ blod of which ix an upper Hessenberg matrix $H_{45}$. The $n$-th iterate is computed as $x_{m}=x_{3}+V_{n} y_{m}$ where $y_{m}$ is caloulated such $x_{m}$ minintzes $\|\left(b-\left.A x_{m}\right|_{2}\right.$. This amouns to cal

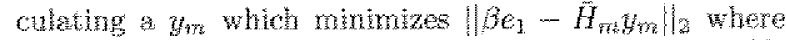

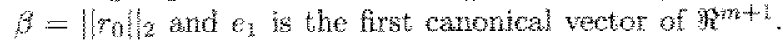
A OR factoriathon employing Givens rotatons - is used here to solve this least souares problem.

The chasick GMES method expands the Krylow subspace dirnensions, iteration after iterator, to $n$ ard terminates in at most $n$ iteratons. Eack iteration pequires every previons basis vectot. A restarted version of GMRES, whe the her hat restricts the expansion to, say, m dirnenglons and restarts the Anold proce dure using $x_{m}$ as new initin guess. These restats are chled the outer iterations. Glven below is the restarted

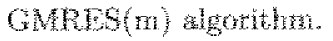

$$
\hat{h}_{0}=0 ; \quad q_{0}=\mathbf{d}-\mathbf{F} x_{0}
$$

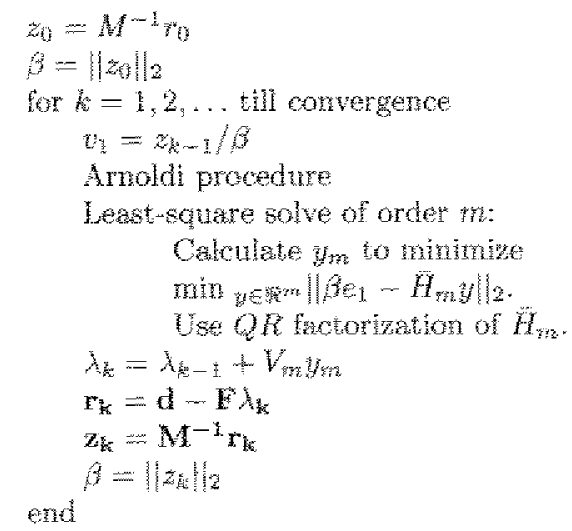

The Arnold procedure is the heart of the algorthm. It requires throsteps. For a given $A$ and an intial vector $v_{1}$, the m basis vectors are constructed as:

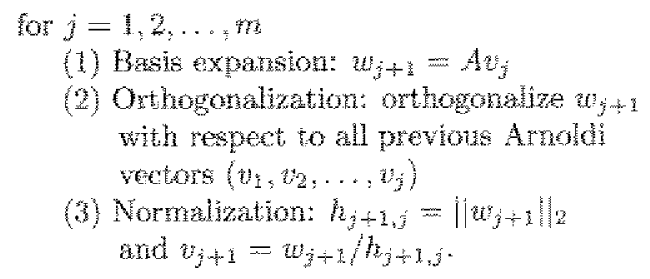

Orthogonaliration is the man step. Tradionaly a Modifed Gram Schmit algonthm is shays prefered at this sey (over Clasten Gram Solmidy) becase of its rimerical stabilty. It is as follows. The symchtonition points are inderlined.

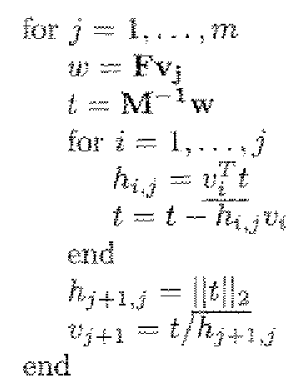

The irst set of points, t.e. the th thalations, presents a high communication "equirement. Withn ach step 7 the vector $t$, once getherated, im imedistely projected to, and subtracted from, each and every one of the prevous Amold vectore $\%$, Whoh projection, a veotor inmer product, requires a slobal symehonzation. In a Classien Gram-Schmde, the projectors and the substraction steps cond be catred ont separtely, with angits synchronizator step in betwen. However, bocuse Classcal Gram-Schmd is wastahe (though mathemat icaly watwelest to Modhed Gran-Senndt, a seond orthogonduzation step is neded. Thus, he thal teo othogonalized Cossical Gram-Schmid algorthn is as collows. 


$$
\begin{aligned}
& \operatorname{tor} j=1, \ldots, m \\
& \omega=\mathbf{E} \mathbf{v}_{3} \\
& t=\mathbf{M}^{-\ddagger} w \\
& \text { hor } \dot{t}=1, \ldots, \dot{j} \\
& f_{k, j}=z_{i}^{T} t \\
& \text { enct } \\
& \text { Gota synchronzation } 1 \\
& \text { for } i=1, \ldots, j \\
& t=t-h_{b}, v_{j} \\
& \text { end } \\
& \text { for } i=1, \ldots, j \\
& h_{i, j}^{2}=v_{t}^{T} t
\end{aligned}
$$

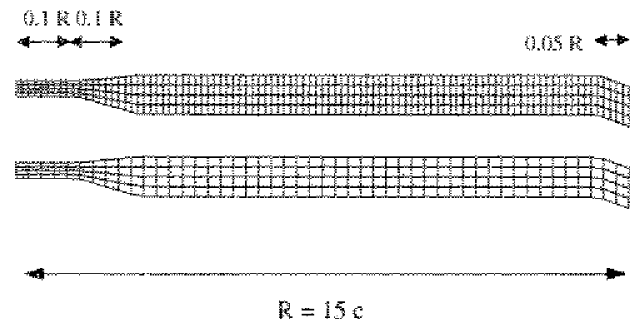

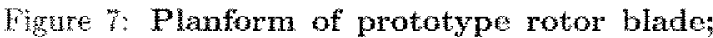
$c=0.53 \mathrm{~m}$; two different spanwise grid resolutions used in this study are shown.

\section{3-D FEM ROTOR ANALYSIS COMPONENTS}

In this section, the man components of the $3 \mathrm{D}$ ro tor Fen andysis are desctibed. They are the genetry and yrids, partiton and comer selection, steady hover prototype, and the ranshent forwart figh prototype.

These are mere prototypes becanse we do not use real airloads, do not have a bim nechanimm, atsd do not have at present a truf representation of a blade structure.

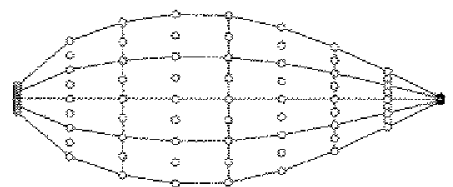

Figne 8t Crossimsection of prototype rotor blade, $5 \% \mathrm{t} / \mathrm{c}_{\text {, exagerated scale: }} \times 4$ bricks with internal nodes.

In addition, for researeh purposes, we will constere only small size problems, with which a latge number of cases could be constructed using the 48 processors that were at our disposal.

On the other hand every fundamental aspect of the physics of the structural dynamis of an walated rotor blade is incorporated. And, the parallel sothton proce ture is gereric, ine. it independant of the type of atrloads, control angle variaton, grid, and material consttution. The objectue is to study the numerical sealability of the Newoth- Krylow solver and the pracical scalabity of its present implemention.

\section{Geometry and Grid}

We consider a hingeless rotor blade, discretized as shown in pigs. 7 and 8 , whe simple grid generator for this study requires that the crossectional discretization remains the same along span and that all sectors be solid. With these assmptions, it is straight forward to accomodate an arbinary variation of antol shape, twise, planform, and advanced tips. A key limitation at present is that only one conthus structure can be gridded. Grid generation, however, is not the focus of this work. It is assumed at the sutable grid will be avalable to the solver from other sources.

The sufface geometry, required for external forcing, is defined by the sectional airfol coordinates. We use a generic, symmetric airfol with $5 \%$ thidness (Fig. 8 ).

We consider a set of four finite elenent discretizatons. $n \times n \times n$ refers to mumbers of elements along span, chord, and thickness. Note that eack elernent contains 81 degres of freedom and 64 integration points.

\begin{tabular}{|c|c|c|}
\hline Grif & $n_{3} \times n_{2} \times n_{3}$ & Tota DOF \\
\hline 1 & $18 \times 4 \times 2$ & 12,060 \\
\hline 2 & $18 \times 4 \times 4$ & 25,920 \\
\hline 3 & $96 \times 4 \times 2$ & 25,920 \\
\hline 4 & $96 \times 4 \times 4$ & 46,606 \\
\hline
\end{tabular}

Table 9: 3D FEM Rotor Grids

Fach finte element, naturally, can scomodate ibs own constitutwa riaterial model and ply diredion.. we 
use simple isotropic properties: $E=73$ GPs: $H=0.3$ and $p=2700 \mathrm{~kg} / \mathrm{m}^{3}$ (corresponding to Aluninum).

Along with the dinension $c=0.53$, these generate similar order of megnitude non-dinersional values of stifness and mertia as soft inplane hingeles rotors. No attempt is reade to place the sectional of sets with respect to quarter-chom. Thus, the blade may not be dymanially stable. However, the values will genetwe typlcal deflectone witi wpinal sirtodis. The ariosts ate an whifom $400 \mathrm{~N} / \mathrm{Mn}^{2}$ beselne (around $375 \mathrm{lb} / \mathrm{th}$ along span baseline, and two and four ines that amount, to generate large deformation casea. The arload imposed on the blade are preacribed whey act only on the top sumface and they ate zormen pressure antowds. Thus, they have the non-inear charactenstes of alower force i.e. they act nomal to the detomed surface which is not know a prori. The rotational speed is $\Omega=27 \mathrm{rad} / \mathrm{s}$ (steary).

\section{Grid Partitioning and Corner Selection}

The partitionind requirements are nuque - not just ary partitonet will do. The gereration of subtomain grids rom a global grid via a re-calculaton of the finte element connedivites is straghtorward. Partinoners are widely avalable in puble doman, that carry out this task inteligenty ensuring an optimal balareing of processor lowdk. However, for structures, this is not the mose imporant requitenent. The mot imporant re curement is that the the conse problem be piched to enstre a null kemel in every substmeture.

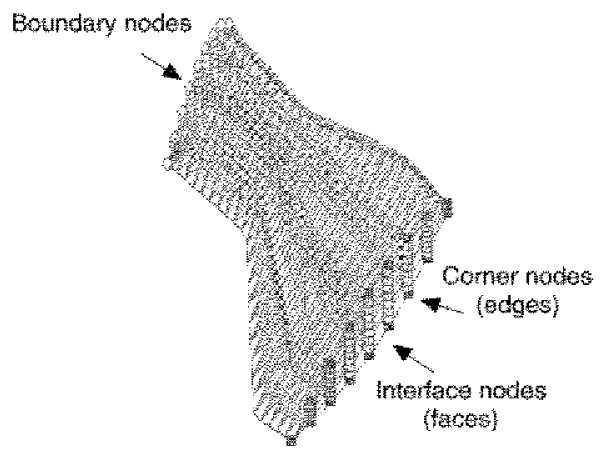

Figure 10: Substructure node designation fot one-way partition.

The partitioner we tevelop as part of the research is simple - in that if hatdes only the brick elements we developed, and it rakes the same asumptions on the grid bpe as orr simple grid garerator. Namely that the cross-sectional grids must rematn same throughout the span, regardess of wations in geometry.

Figute f(a) shows a type of generic 2-D partich that is uses in the present study. The blade an be dithded into any muber of shbotructures in the spanwise

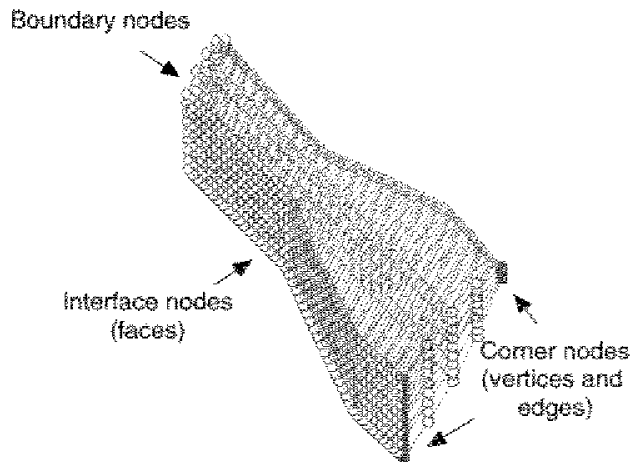

Figure 11: Substructure node designation for two-way partition. Comer nodes are edge nodes connecting more than two substructures and those occuring at the bommaries.

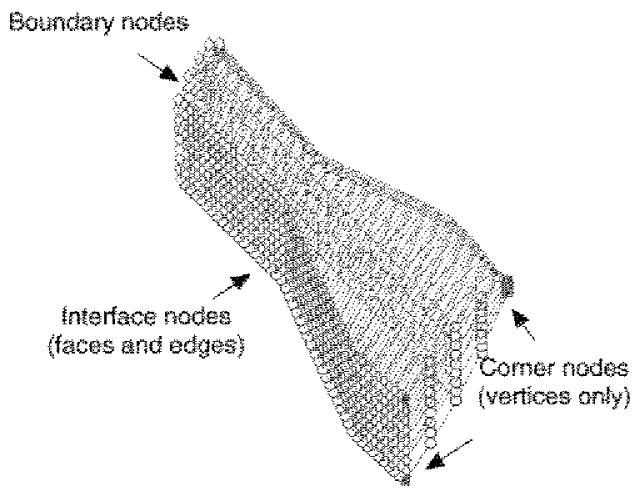

Figure 12: Optimal substrteture node designation for wo-way partition. Corner nodes are vertex nodes including those occuring at the boundaries.

and chordwise thections. Figtre $9(\mathrm{c})$ shows an alternative $1-0$ partion. It will be show that the latter, though natraly low balenced for a blate structure. is a poor partition and should not be thed.

The partioner pertoras the lolowing tasks:

1. Designates the comer wodes.

2. Reotere the sthdomain rodes into interior, face, edge, vertex, and bondary nodes. Recalculates the subdomain fnite element conrectivities.

3. Sets up domain connectivivy natper for subtruture to substrueture communuication.

The frst and second are the key tasks. The thres is merely a water of bok keping. 


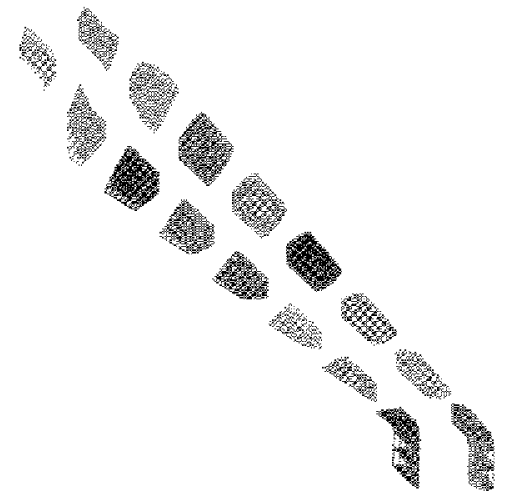

(a) 2-13 partitioned bade grit

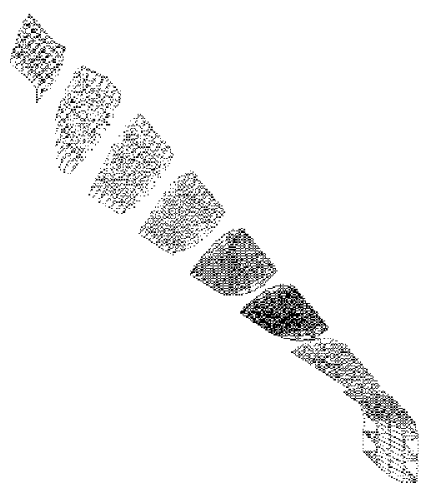

(c) I- Depritiond blate grid

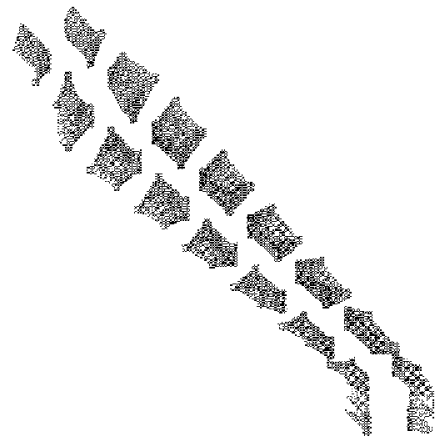

(b) Corver and inerected frodes

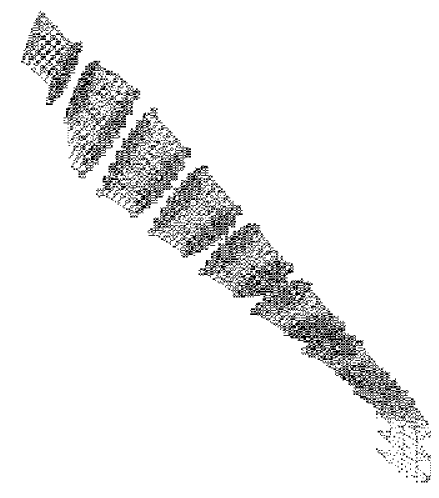

(d) Conters and interence nodes

Fene 9: Partitioning of blade grid into substructures or subdomains. The corner nodes must ensure a null kethel for each substructure. Each substrueture will be solved in a separate processor. 


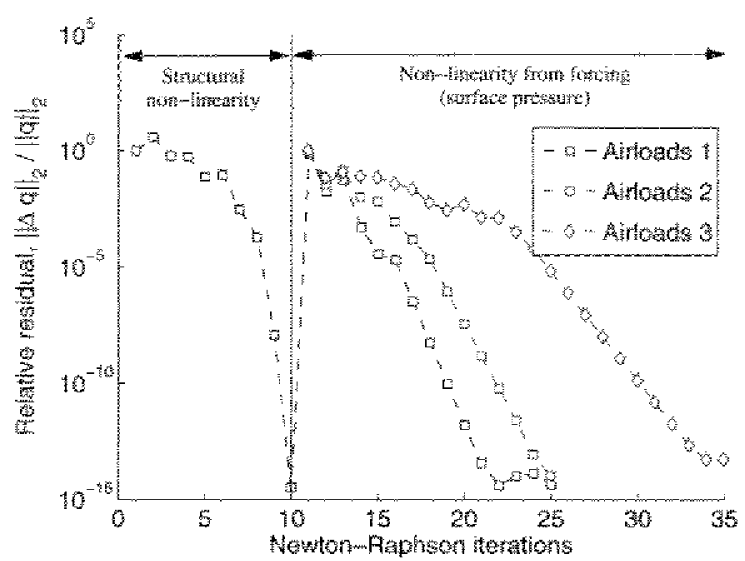

Figure 13: Convergence of NewtonRaphson outer iterations for structural and forcing non-linearities in hover

\section{Corner Selection}

For a generic $3 \mathrm{D}$ gubstucture, each interface wode can be a face, edge, or vettex node. Of these, the edge and vertex nodes, that are common to mote than two substructures are designated as corner nodes. Now consider the 2-way partition of $\mathrm{Hg}$. 9(a), The nodes on the subdowain edges are immediately designated as comer nodes. It is clear, however; that this definiton makes the two subtrutures at the tip end (or extremeties of the tip end in case of more than two chordwise strips) indehnite. Wad substructure then carries a potational rigid body mode. Thus, the definition of corner nodes most include in addition, those edge nodes, that are common to only two subdomains, wat which oecur at the boundaries of the structure. With this definiton, the corres nodes are now as shown in Fig. 9(b). This defintion also enables the selection of comer nodes tor the i-D petrtition ir Fig. $9(\mathrm{c})$, otherwise, thene would be no cor rer nodes. For a very largenseale 30 poblem, a large number of coner zodes is generated by this procedure, leading to a moderately large coarse problem. A superion chotce of cormer nodes for a $3-D$ problem simply the abuchomain vertices, and like before, additonally those that ocetre the bourdates. There is then atwas a maximum of only 8 conter nodes per subdomaty $\cdots$ regardless of the grid. In this paper the selection is not implemented. We we the prevtous selector as shown in Wig. $9(b)$. Note the comer nodes defne super elements that constitute the contes problem, and, for a $2-D$ parthion the optmal selection can lever the super elements whithut intemal nodes. The concen for element loching wder these dreanstances require a closer examination that hes not ben carred out yet.

\section{Node Reorder}

The pordering bring the intertor nodes frets, fol lowed by intertace nodes, then comer nodes, wnd hety

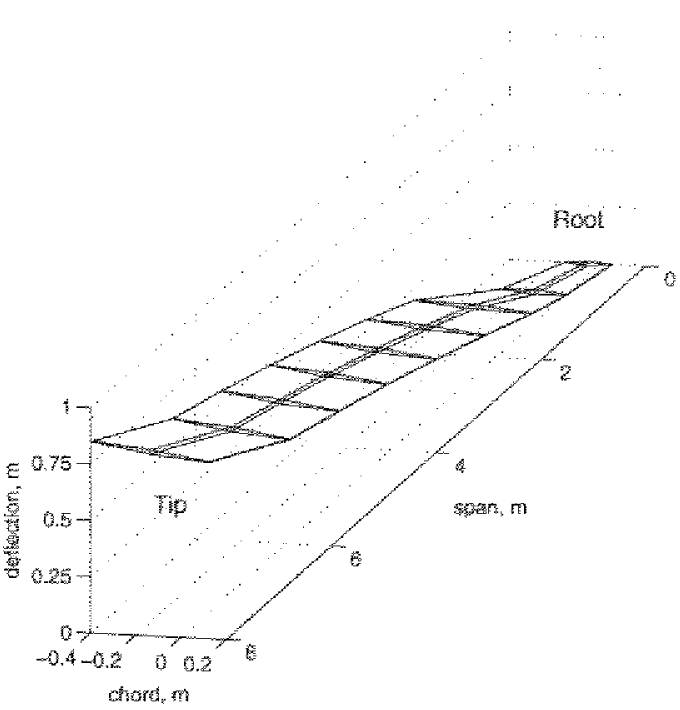

Tigure 1.⿻三丨 Blade steady deflection in hover using prescribed pressure auxloads (only grid outhines are shown)

the boundary nodes. The procedure depents on the grid, partition ( $-\mathrm{D}$ or $2 \mathrm{D}$ ), and the selection of corner noles. The $N$ elemental nodes in exch brick is asooctated whth a roturat withen each subtructure. The natural order is then associated with a reordered order, and its reverse, with an associdion bad to natural. In addition, the watural order is asociated with the global order as the goonetry and material constitution is defrned in the sattert.

\section{Domain Connectivity}

Domalu Connectivity is merely a matter of bookkeepins. For a Lagrangian problem, the connectivity re mains static, and reeds to be calculated only once for a grit. Becane of the non-foating non-overlapping. and conforming nature of the partitons and elements, there are no search, interpolstion, or projection recura. ments. Consequerty there are no errors introduced dur ing substudture to substracture communication. Wach substructure carries destmation map and a reception map. The destination ma conting the substrebres to which quaticies are to be dispatched, and the intermal note umbers to which they correspond. The reception

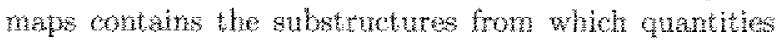
are to be receved, and the interal rode number to whick they whil correspont. 


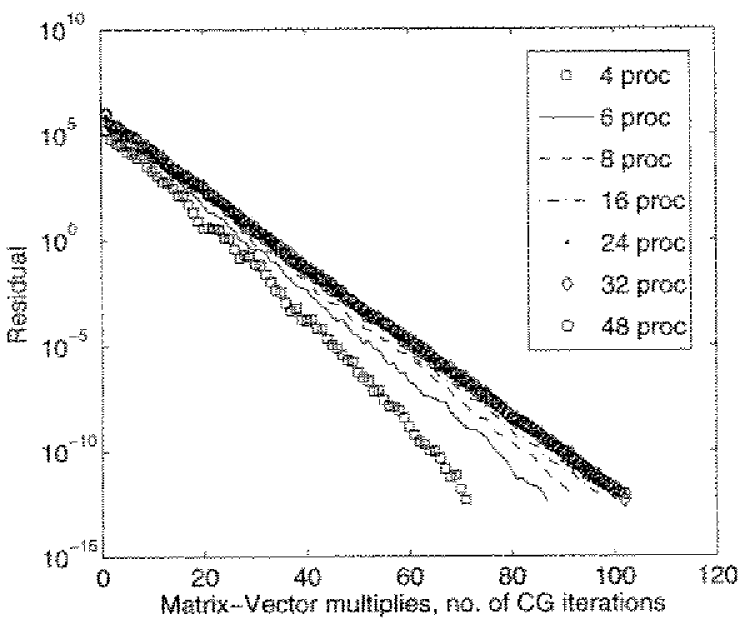

Figure 15: Convergence pattem of FETLDP/Preconditioned Conjugate Gradient updates for simulations of 4 to 48 processors.

\section{Steady Hover Prototype}

The seady hover (ideal) prototype simply solves for blade response using a proschibet pressure airloak at a constant collective angle. The non-inede solution procedure uses Newton-Raphson outer iteratione arond

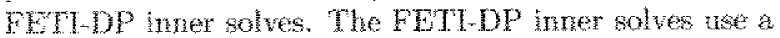
Coniugate Gradient (CG) apdate in hover. "This is adequate ha whe sifwess matrix is symmetric.

Several initia updates of the stifness matrix nre necesary to include the non-1mear stmetural stifness -... which provides the koy extension-bending non funeariby associated with rotation. Fure 13 shows the convergence of this non-linearity in the intial part of the plot. Around 8 to 10 iterations are regured for a thent con vergence. Stubsequently, the rotor stifness matrices can be updated ony at certain intervals if dested, whle usIng modified Newton in betwen. Once the struetural non-1neatien are converged, the pressme arroats are mposed on the blade. The convergetce of the airhod it eations are bown in the same pot in the righ hand side. The two parts are separated as conceptualy these are Dudustrutare iterations where the geometric stifness need not be nplated. The results shown, however, are with fuly untated strfineses in every theraton. The direction of the pressure airloads is deformation-dependnt

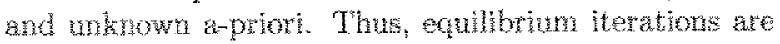
required.

In exach iteration, the virtual work is catentated hased on the previous deformation stete. An ahemative and mone rigorota, approach is to linetize the foreirg usng incremental displaeerents. This leads to a nonsymmente sthness contributon. which is lowever eas

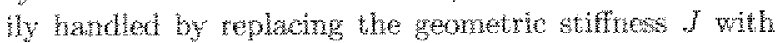
$1 / 2\left(J+y^{2}\right)$ as the role of the stimese is ony to conerge the Newton iterations. However, iteratons she stil hec-

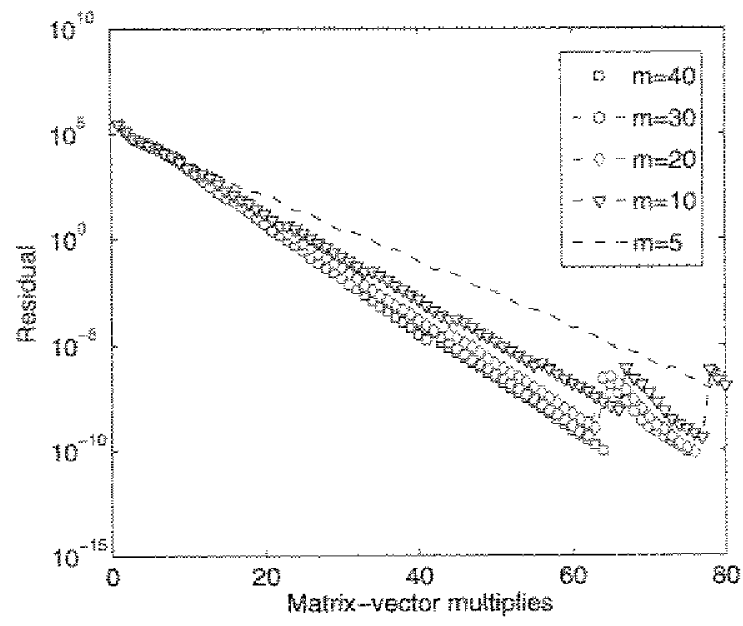

Figure 16: Convergence of GMRES uplates for various restart numbers; all calculations use 32 processors.

essary and therefore we belleve the previous confguration approach is more effcient. The relatively large deformatho corresponding to arloats 3 is shown in Fig. I/t.

Within ach Newton iteration is the Krylow solver, TET-DP with $\mathrm{CG}$ updates. The convergence cheris is set thently to $10^{-12}$ for all cases in this study. Fis. 15 shows the convergence of the bolver when run on 4 to 48 processors. We wit always show the conergence corresponding to the hrst Newton iteration as thegrew with a zero guess and takes the most mumber of iterations. The scalability (fxed problem size) of these calculations are examined in more detal in the next section. Here, we note that the mumber of teration increase with an increse in the number of processors, but only gradualy - the feature of an algorimm where the precon ditoned interiace problem grows slowly, and only at a polylogarithme tate whth increase in the mubar of subdonains. Plysicaly, it means that the increang corrse problem allows a geater transer of subatructute infor mation across the global structure.

\section{Transient Forward Flight Prototype}

The transicht forwad flight prototype solves for blade response using the same set of prescribet pressure

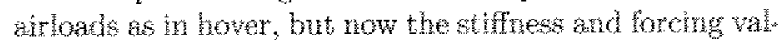
ues are those that arise on of a single time step in a whe marching procedure. We consder a Newmatk scheme

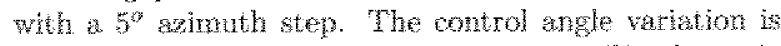
taken as $\theta(b)=20^{\circ}+50^{\circ} \cos b-5 y^{\circ} \sin$. The dyamic stifnes now contans the complete mertid terms and

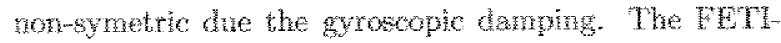
DP inner solves now use Generdized Mimmun Revi and (GMRE) update.

The matrix structure will be tatentical in every time step, whefore, tor purposes of scateblity stury it it enongh to conider only one. Issues related to parallowa 
hon arise immediately be to the presence of the Amold algorthm with GMRES. The issue, its resolution, and

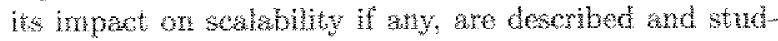
led in dexil in the next secton. Unike CG where each updabe require only two previous npates for construction, ir. CMRES, each update requre infonmatow from cwery provious updates. for example, as shown eatler in Fig. 15 in 100 iterations are tequired, 100 such vectors have to be stored. A staniard procedure is to use a restarted version where only w previons apdates are used at a the. Once at set of m updates are obtanet gin estimete of the solution is constructed. The m updats are then throm away and the construction of a new set begins with the current stmate of the solution.

Figne 16 shows that for the smant grid size used kexe, the convergence pattern is similar over a browd range of restart paraneter -... aven $m=5$ is adeguate to obtain convergence. For pumoses of a realitic scalabilly gtudy, however, we will consider $n=30,40$, and 50. These are deemed adequate for large-scale structum confguration with dense interface matrices.

\section{SCALABIUTTY OF 3-D ROTOR ANALYSHS}

The scalabity of the 3D FEM parallel solver is re ported here in detail. The first section is relevent to the steady hover prototype. The Krylov solver uses a $\mathrm{CG}$ update here. The dea of substrueture optmality and fefintion of scalability is introduced here. The second section is relevant to the transient forward fight prototype. The Krylov solver is equpped with a GMRS update here.

\section{Steady Hover}

\begin{tabular}{|c|c|c|c|c|c|}
\hline$n_{3}$ & $\mathrm{EE}$ & $\begin{array}{c}\text { Subdom } \\
\text { HU }\end{array}$ & Conse & $\begin{array}{c}\text { FETIDP } \\
/ \mathrm{PCG}\end{array}$ & $\begin{array}{l}\text { Solver } \\
\text { total }\end{array}$ \\
\hline 6 & 201 & 757 & 130 & 775 & 1668 \\
\hline 8 & 200 & 468 & 91 & 622 & 1180 \\
\hline 12 & 199 & 246 & 68 & 158 & 770 \\
\hline 16 & 194 & 165 & 52 & 361 & 580 \\
\hline 24 & 191 & 96 & $5]$ & 267 & 416 \\
\hline 32 & 190 & 66 & $\pi 1$ & 213 & 350 \\
\hline 18 & 190 & 39 & 168 & 187 & 395 \\
\hline
\end{tabular}

Table 10: Solver time vs. number of substructures on a single processor

Consider the grid of sze $95 \times 4 \times 2$. If is partioned irto 6 to 48 substactures asing a 2 -way partitioning i.e. wubtructure arrangenent simnar to $\mathrm{Fig}$. $9(\mathrm{a})$ hat ing $3 \times 2$ to $24 \times 2$ block. The sower time tor cach of these problems are shown in Fig. 7 . The mportwee of substucturing is immediately appanat. There is a steep drop in soluton the whith imereasing number of substructures. For any proben of a fred size, a condi

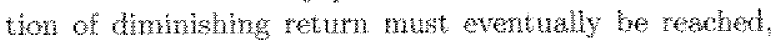

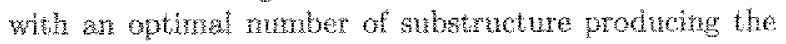

\begin{tabular}{|c|c|c|c|c|c|}
\hline$n_{s}$ & $\mathrm{FE}$ & $\begin{array}{c}\text { Subdom } \\
\text { LU }\end{array}$ & Corate & $\begin{array}{c}\text { FET-DP } \\
/ \mathrm{PCG}\end{array}$ & $\begin{array}{l}\text { Solver } \\
\text { total }\end{array}$ \\
\hline 6 & 32.6 & 121.80 & 21.56 & 94.07 & 237.87 \\
\hline 8 & 24.2 & 57.44 & 12.33 & 57.28 & 127,28 \\
\hline 12 & 16.2 & 20.95 & 5.80 & 26.85 & 58.73 \\
\hline 16 & 126 & 10.54 & 3.61 & 11,93 & 29.19 \\
\hline 24 & 8.18 & 4.16 & 2.71 & 7.96 & 14.89 \\
\hline 32 & 6.01 & 2.20 & 2.92 & 5.70 & 10.85 \\
\hline 48 & 1.24 & 0.88 & 3.62 & 5.15 & (s.70 \\
\hline
\end{tabular}

Table 11: Solver time vs. number of processors; each processor contains one substructure.

minimum solution tine for that problem size. We shat call this the substreture optindity runber. For this protelen it 132 . Note however that the rise in solution the beyond the optimulity point is not reerly as stwep as its decine phor wit, and there is a larye region over which it remans fiat. For this problem, this region is betwen 16 to 48 stbstructures. The fat region is a gitt of theratwe subtructuring. It is shown later that this re

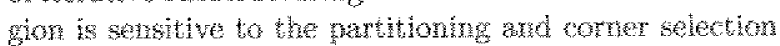
procedure, A good partitioner and coner selector will keep this region fat, anor one will produce a steet rise.

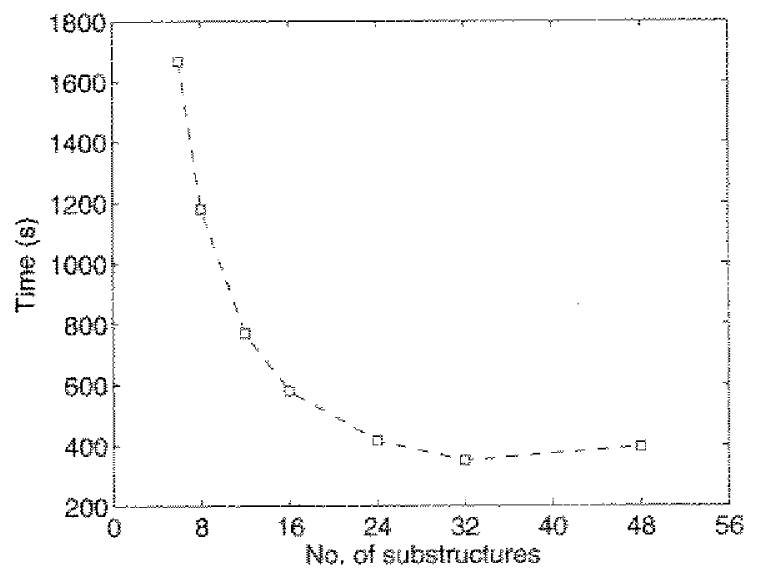

Higure lit Solver time vs. number of substructures for calculations on a single processor.

A. paralle implenentation solves each substructure on a separate procesor. Note that, it is importat to calculate the spees-1w obtaned, wing the single proces sor tine wh the same number of stbstructures. That is, the solver time with, say 32 protescon, mut be com pared with the conterponding solver time on angle processor that use 32 substruttres. This is to ensure thet computatione of the same complexity are compared, oth

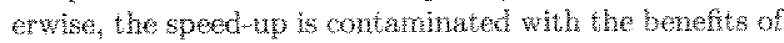

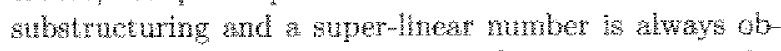
tainet. This is because using 32 sthetwetwe on a singie processor by thed reduces the solver time by mone than $32-$ a fuct that has nothing to do with paxalleliza 


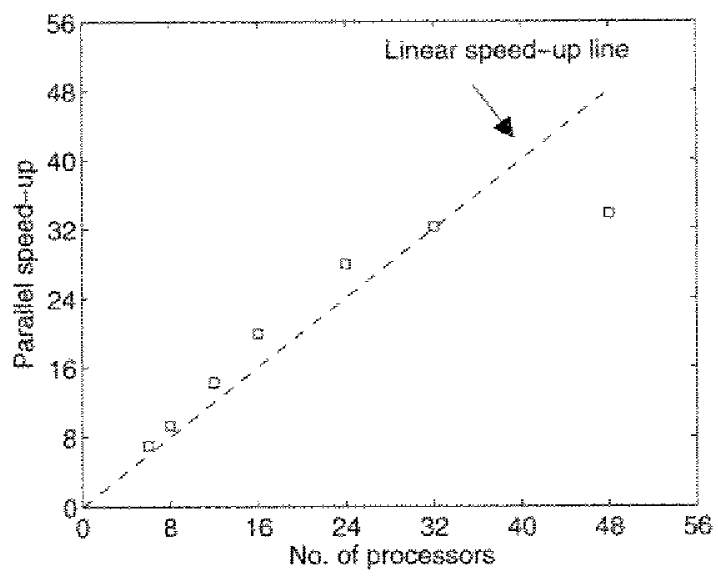

Tigure 18. Parallel speed-azp for calculations on multiple processors; each substructure solved in a separate processor.

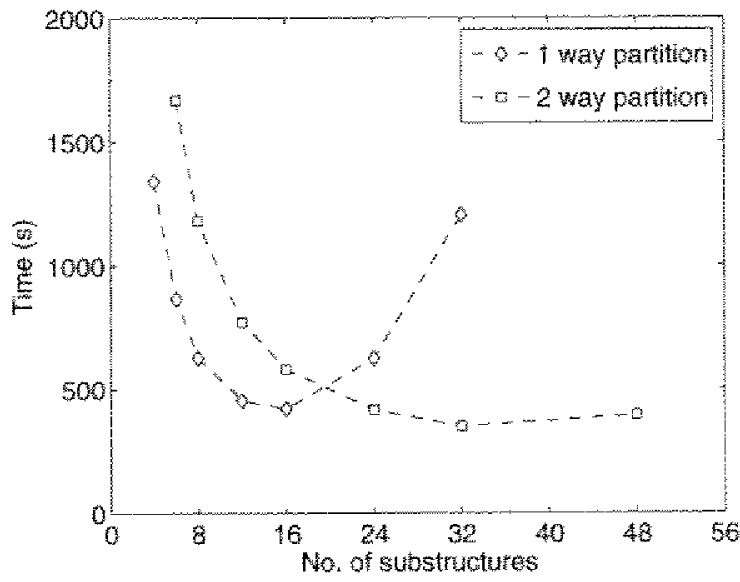

Figure 19: Efect of grid partitioning and corner selection on solver time as a function of number of substmctures; calculations on a single processor.

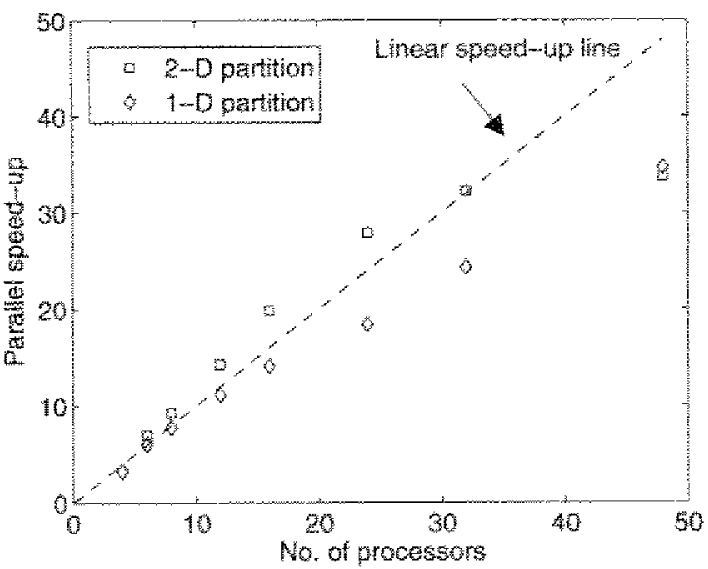

Finure 20: Effect of grid partitioning and comer selection on patallel speed-up for calculations on taultiple processors.

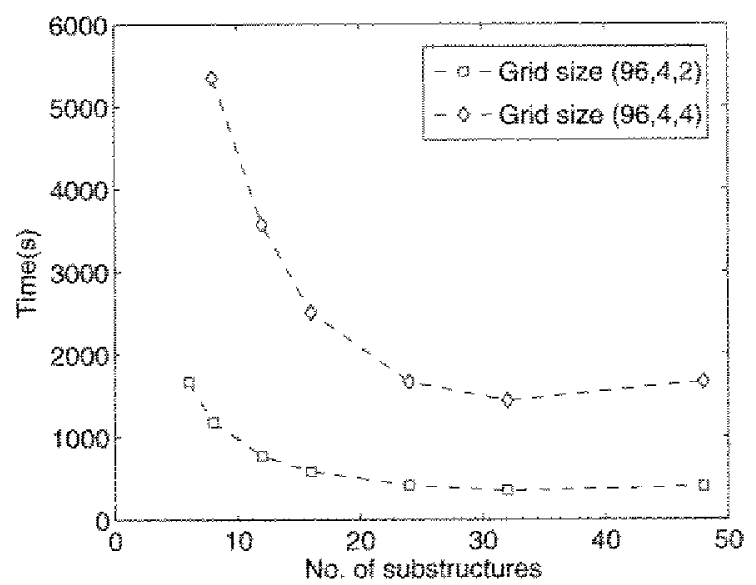

Figne 2: Two different problem sizes with the same substructure optimalty; solver time ve. number of substructures on a single processor. 
ion but substructuring itself. The paralle speed-up is shown in Fig. 18. Ever for this fixed problers size, it has a perfectly linear trend up to the point of substruxture optimahty. Note that the point corresponding to 32 procescrs has nothing to do wh the pont correspond ing to 16 耕ocssors. Inded, the 32 processor rur takes aly $10.8 \mathrm{~s}$ whereas the 16 processor rum takes $29.2 \mathrm{~s}$, i.e. less than hal the trme. What the sped-up plot shows is

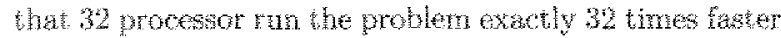
compared to a single processor using 32 substructures.

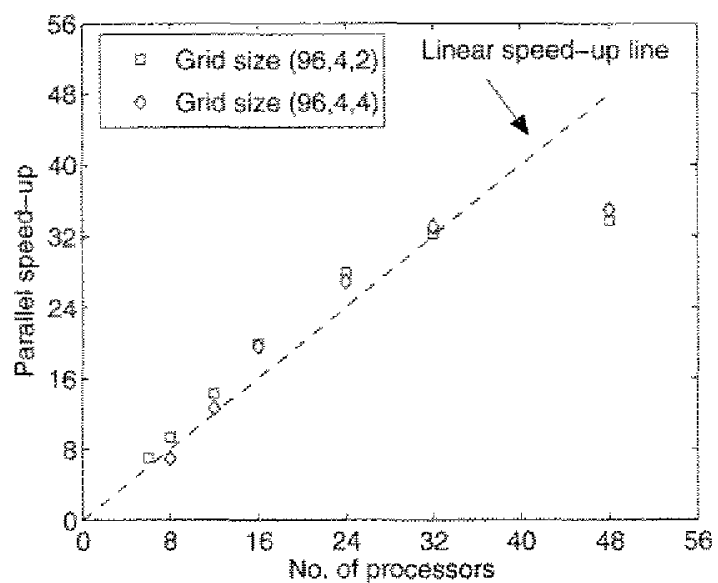

Figure 22: Parallel speedmp for problem sizes with the same substructure optimality; solver time vs. number of substiwuctures.

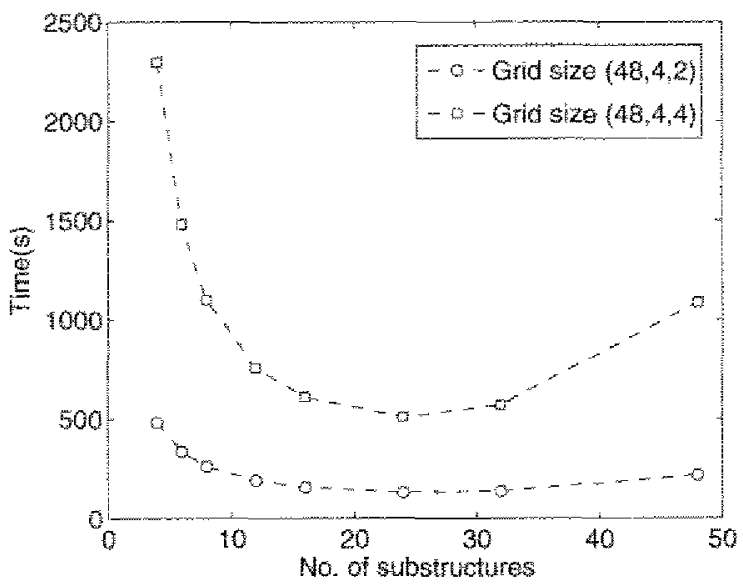

Figure 23: Two different problem stzes with the same substructure optimality; solver time vs. utumber of substructures on a single processor.

The drop of in scalabily beyond 32 procesons is studied using the exact timings for the diferent parts of the conputation. The things for the single mocesw sor and paralle colchutions are given ir Tables 10 and

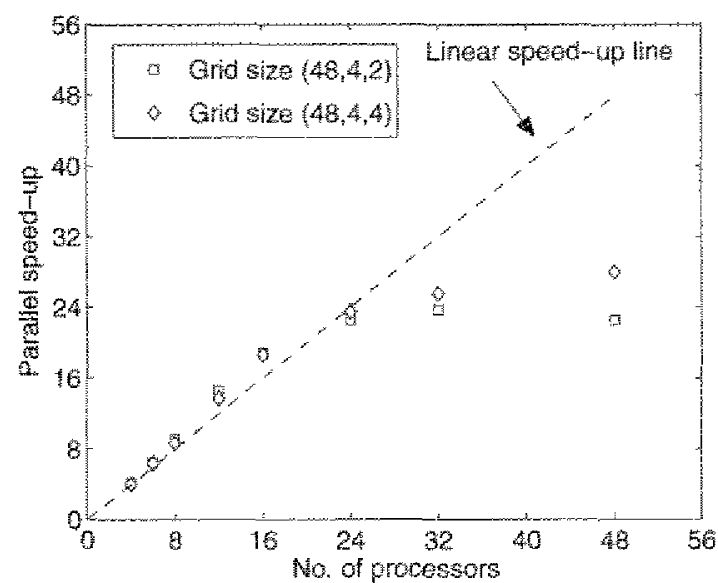

Figure 24: Parallel speed-up for problem sizes of same substructure optimality.

重. In the tables; ' $\mathrm{C}$ ' refers to the time taker to construct the struttural matrices. 'Solver tota' refers to the total solver tithe. The two together constifute the to tal simulation time. The Solver total time consists of thee parts: (1) 'Subdom LU' time, which refers to the subdoman factontation, (2) 'Coarse' time, which refers to the coarse proten factorzation and communication, and (3) the 'FLTIDP/PCG' the refers to the Krylow solver time. Note that the later indudes the computation and communication costs of the resictual, meconditumer. and matrix-vector mitples, and the additone commricktions rectured for the updates. The communications costs are, of course, incurred ony turing the parallel calculations.

Fram Trble 10, which shows the single processor twolngs, the reason behind the flet region in clear. The growth in the coarse problem is of set by the reduction in the Krylov solver time. This is as expected w as the purpose of the conse problem is precisely that -. but the man point is that the conse solver shoute be Just onotgh to serve this purpose ath no larger, so that the stbotructure optinaliwy is pusted to as high a pro cessor number as possible. Beyond the optirnality point; any growth in the coarse problum is an indeator of increated communication cost for the parallel imptertenbaton. Note thet the coatse problem is solved th every frocessor and as suen, recuires global communication. The drop of in Fy. 18 is a direct consequence of this commmication ost. To summarize, a key objective of the coars problem shonld be to kep the growt beyond substructure optimality to as gradual as increse as posshlo. This hes no bearing upon scalability wh respect. to problem size, lytit serves to exterd linear speed a fixed problem size to ac high a proceson number as passibles.

Wo inlustrate the inportance of the coarse prob-

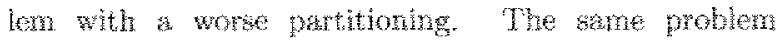
when treated whth a 1 -tay partioning as itostuded in 
Figs $9(\mathrm{c})$, M(d), and 10 , generates a timing and atala bllty plot as shown in Tigs. 19 and 20 . The 2 -way par thioning rewhe are atso plotted for comparison. Clearly, from Fig. 10, the sure problem now has atbstucture optimality of 16, as opposed to 32 . A good parallet im plementation shond ganranted a linear speed-up at least upto 16 processots. Scalablity beyond the rumber is ex pacted to be affected adverwely by communtction costs of the coarse moblen. This is exactly mhat is observed in Fig. 20.

The linear speed-up range is not a huchon of problem size but of subatructure optmally. Por example, Figs. 21 and 22, compares the single processor soluton time and parallet speed-up of a bigger problem of aize $96 \times 4 \times 4$. From the single proctscon solution time, it is cleat that the substructure optimalty is an 32 . As a resilt, the linear speed-up renge still extends only up to 32. The same concusions hold for very snal problen stzes, ats shown in Figs. 23 and 24. The smallest grid of $48 \times 4 \times 2$ still shows a linear speed up up to 24 processors equal to its value of subutructure optimality. In the same mannex as a trid of $48 \times 4 \times 4$ which is twioe its size.

In summary, for a given problen size, the present solver shows a perfectly linear speed-up - lot at least as many procesors as its subtructure optinality. To extend this linear speed-up range, a smaller conte problem is reguired. An example of such a seloction was shown earlier in Fig. 12.

The scalability with increasing problem size in ilhstrated in rable 12. Problem 2 has twice the size of Problen 1. Problem 3 has sare size as Probter 2, only different grid characteristics. Problem 2 and 3 therefore have simbr solver thes, up to substructure optinality which sets in at 24 processors for Problem 3 . The timings of Problem 1 and Problem 2 provide a simple ilnustration of scalibily with noresing size. Because Problen 2 is twice the size, twite the number of processors provide an approxinately sane solve time. For example, problem 2 on 12 processors take similax time as Problem 1 on 6. Problerr 2 on 16 take similar time as Problem on 8 .

\begin{tabular}{|c|c|c|c|}
\hline$n_{p}$ & $\begin{array}{c}\text { Problem 1 } \\
48 \times 4 \times 2\end{array}$ & $\begin{array}{c}\text { Problem 2 } \\
96 \times 4 \times 2\end{array}$ & $\begin{array}{c}\text { Problem } 3 \\
48 \times 4 \times 4\end{array}$ \\
\hline 6 & 31.52 & 237.87 & 232.00 \\
\hline 8 & 28.39 & 127.28 & 126.70 \\
\hline 12 & 1307 & 53.73 & 35.43 \\
\hline 16 & 8.22 & 29.19 & 32.72 \\
\hline 21 & 5.73 & 14.89 & 31.69 \\
\hline 32 & 5.70 & 10.85 & 22.26 \\
\hline 48 & 9.62 & 11.70 & 38.89 \\
\hline
\end{tabular}

Thble 12: Parallel solver thes showing sealability with respect to problem size up to limits of substructure optimality.

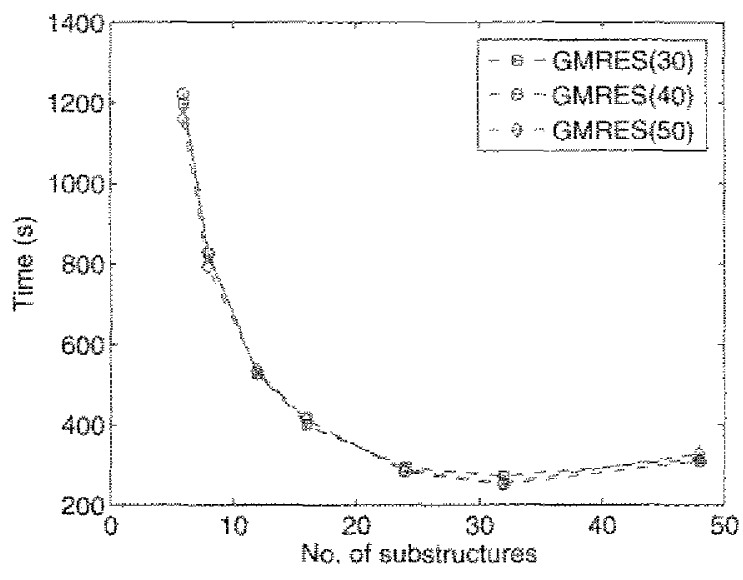

Figure 25: Solver time vs. number of subm structures on a single processor; FETIDP/PGMIES.

\section{Transient Forward Flight}

The same conclusions on effective partitioning and substructure optmalty are carred over in this section. These resulds, which are very simitar to those shown in hover, are not repeated. The scalability results of a strigle grid size $96 \times 4 \times 2$ (with subtructure optmality of 32 ) is presented hepe. The results for the ofher grids compare similarly to hover results.

\begin{tabular}{|c|c|c|}
\hline$n_{p}$ & Modifed GS & $\begin{array}{c}\text { Crasical GS } \\
\text { with Roort }\end{array}$ \\
\hline 6 & 194.08 & 190.17 \\
\hline 8 & 109.47 & 100.47 \\
\hline 12 & 41.69 & 41.43 \\
\hline 16 & 23.92 & 24.24 \\
\hline 24 & 12.33 & 11.77 \\
\hline 32 & 8.88 & 8.61 \\
\hline 48 & 10.67 & 10.04 \\
\hline
\end{tabular}

Table 13: Parallel FETI-DP/PGMRES solver times (secs,) with Modified Gram-Schindt and Classical Gram-Schirudt with Reorthogonaliza tion based Arnoldi proceduras.

The scalabilty of whe paralel FETH-DP/PGMRES solver inwolwing the non-symmetric matrices in forward fight shows as lnear a trend as those of the FETlDP/PCG alver in hover. The single processor timings are shown in Fig. 25. All calculatens we the Roorthogonalized Chastcal Gram-Schmd Arnold procedure. The increasing vegtart parameters all whow the same wnings on angle processor $\cdots$ as expected, becunse their affect is anly on nemory - but inem increasing communation costs tor a paralel calculation. However, for the small

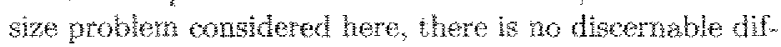
fermoes between the thee versions even in parallel. As a resul, the suablaty plot show in Fig. 26 is identical for al three cases. Inded, ever the Nodifed Gam-Sobimdt 


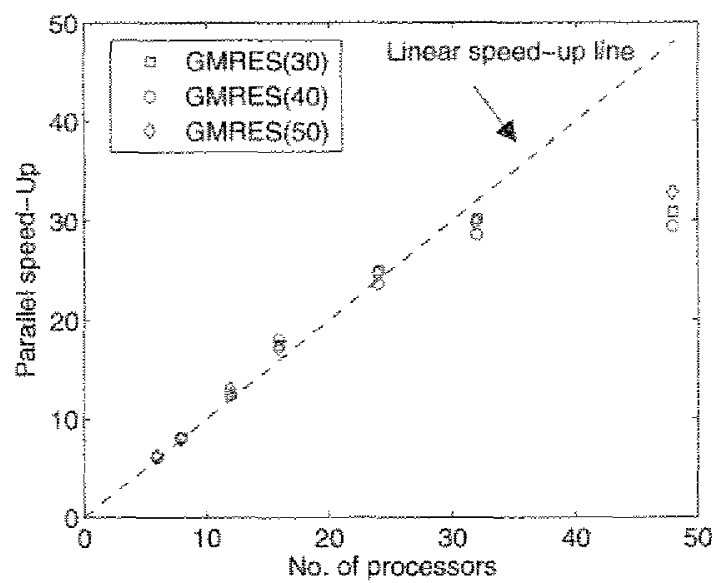

Figure 26: Parallel spoedmap of FETIDP/PGMRES solver using Classical Gram-Smidt with Reorthogonaluation based Arnoldi poocedure.

procedure show the same scalablity behavor. The lat ter is expected to be drasticaly inferior for large subdo man probleme Note however, regardles of sealabilty, the axtual solution times for Reorthogonalized Olassical Gran-hehind are by themalves lower compare to the Modifed Cram-Sehindt. 'This difference is expected to be drastic for large seale problems. This tretd is clear in Table 13 , where the former provides a marginally faster timing trend. Given the small size of the problem, a concrete conclusion is still premature.

\section{CONCLUDING OBSENVATIONS}

A 3-D FEM analysis for rotary wing dynamics was formulated with explasis on the inertial terms unique to rotoronft. A dual primal itertive substructuring based Krylow solver was developed for a fully parnllel solution produre. The FEIT-DP doman decompositor agorithm wh used for this purpose. The agorithm was equipped with a GMRS update, in addition to its traditonal $C \mathrm{C}$ baed implementation, die to the minue nor symmetric nature of the notary wing inertial terms. The scalablity of this alver was studied in fetal both for howe and transient romard fight prototypes. The key components of rotorchat analysis: multibody $\mathrm{dy}$ nanice, periodic response solution, blade alloads, and hence tin were not part of this study. The focus was purely on the scalibility of a $3-\mathrm{D}$ FEM based large scale structurat dymarmo anslysis. That is the key contribu tion of tris paper. The following are the key conchsions of this struty.

\section{Key conclusions}

1. Given a fxed problem swe, thero is always an op timat number of enbetructure or subdomaine into which the problem can be sab-divided so as to re

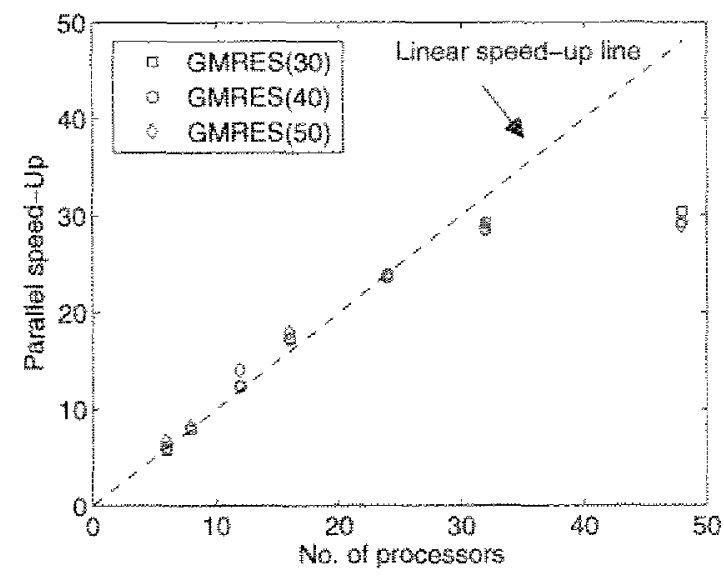

Fisure 27: Parallel speed-up of FETTDP/PGMRES solver using Modified Gram-Smidt based Arnoldi procedure.

quire the minimum solution the. The stodoman optimality grows with problem size. Weyond this optimalty, the benefits of maller shed subdomains are offet by the inereasing interface. "Ths has less beating on scalability but is critical for the actual solution bme.

2. The present imptementation of the $3 \mathrm{D} \mathrm{FEM} \mathrm{rotor}$ code is schloble and shows a linear spedi-up. That is, an p-processor calculation with a separate sub structure in each processor takes $1 / p$ the thme compared to a single processor whth p-stubructures. It also seales with problem size. That is, a n-times larger problem takes sinlat time whth $n \times p$ processors. For \& fxed problem size, a drop off in scalabito ity eventualy occurs -.. but not before the sabdoman optimality muber is reached. A that point, there is no reano to use any more procesoms -.- unless a farge probtem is atacked - in which case, lnewr speed-up is restored again up to the new optimum. However, evan in more processons that optimun is used, the scalablity only reaches slateau, and does not show a dramatic drop oft.

3. This platean stems from the nature of iterative substructuring. Uripe chassical sulstucturing, here, there is a flat region in time ve. substructure curva, such that the penaly moured by wing more then the optimum rimber of processors is very grad ual. Or the oner hand, the difference between the platean and the lnear speed-ipp line stems com two practieal considerations. Fitst, the subdomain to subdomain cormmunication cost, and second, the global course yroblem communication cost.

4. The frot penaty is a minor issue that cannot be avoided. It can be minimzed by by mimining the number of sytuchoution pointe durting the Krylow updates, This is pertnent more to GMREs where 
the wodfied Gram-Seridt algorthm - the nost atable procedure tor renerating the Krylov hasis - in currs a significant communication cost. In bhis paper we have compared the modited Gran-Scridt with a chexper chasical Gram Sernid. The later regnire. ar addichal neorthogonaluing step that is optional and is carred out only when necessary.

5. The second penaty is a major issue. The size of the conrse problem is a key driver of scalabinty "The rule is to select corners which are common to mote than two subcomains. In 30 this generates a very large number. In addtion, depending on the parthonkng, there way not be any comer note at all. rhe key idea is that the number of comer nodes can vary deperding on partitioning but they must be selected to ensire multity of the subdomain kemels. "Thus, aspeciat, smart partitioner is needex, that minimizes the selection of comer nodes while eneur. ing the above requirement. Not just ary partitoner will do. In the present paper this task has boen easis arcomplished manualy, due to the simple nature of the geometry and grid.

6. Finaly, we note, that the fheoreticat condition num ber esimates and proof of optmality in domain de. composition is bused on the assumption of symmet ric and coerive operators with CG updates. They are lest developed for non-symmetric systems - and are usually based on the asumption of the cominance of the symmetric operator. One approach is to butd upon algonthms that are provably optimal for the former to extend them to the later. This is the procedure followed in this paper. We frst ver Ify the performance of the algorithms in ifled hover. We then extend them to real forward flight cordithons. We equip EETHDP with CMRES updates for this purpose and demonstrated optimal conver gence scoliablity petterns computationaly. We do not attempt to provide formal theoretical estimates in this paper.

\section{Thrust Areas for Future Research}

A suggesed hist for buture directions of this research is given below subdivided into three categories.

\section{Fundamental Research}

1. Scable soluton for pertodic dymanics - temporal doman decompositon for bottraty value problerth in time.

2. 3-D $\mathrm{FEM} / \mathrm{multbody}$ dyamics conpled andysis mecherisme and metholology.

\section{Applied Reserarch}

1. Locking tree elements, hienarchical chments, node less elements to falltate $1 \mathrm{EM} / \mathrm{mul}$ body dyamies ardittechture.
2. Exact atad generic 3D thidestucture merfaces.

3. Fxact delte cotpling procedurea for trin solution in level and taming fight.

1. Smat stbatreturng - effecht omer node selection, interface localization, and notal reordering.

5. Interfacing with 3-1 sold geomely and grid tools.

\section{ACKNOWLEDGMENTS}

The authors acknowledge Dr. Roger Stawn's support wr the research at the U. S. Amy Aerofightynamic Drectorte under the High Perfomance Corrputing Instivte for Adwaned Potorcraf Modeling and Simulaton (HI-ARMS). We wimt to thank Prot. Charbel Farkat, Stantore Untersity, for his insightful comments on dua primal sthetructurms. We also thank Dr. Gurb Guruswaryy, NASA Ames Reseduch Center, for his good advice on thM and substructring methods.

\section{REFERENCES}

[1] Prambenieki, J. S., "Matrix Structural Aralysis of Substructures," AAf Journal, Vol 1, (1), Janwary 1963 , pp. $138-147$.

[2] Promienteck, J. S. and Denke, P. N, "Joining of Complex Substructure by the Matrix Fote Wethod," Joumal of Amrraft, Vol. 3, (3), MayJute 1966 , pp. $236-243$.

3) Denke, $\mathrm{P}, 1$, A General Digtal Compter Analy sis of Staticaly Indeterminate Structures," NASA TN D-1666, December, 1962

[4] Argyis, 3. H. and Kelsey, S., Modem Fuselage Anolysis and the Whatic Abroft, Butterworth's Scientific Publications 1 , t. London, 1963.

(5) Turner, M. I., Martim, H. C., and Wekel, F. C., "Further Development and Applications of the Stifnes Method," Matrix Hethods of Strichum Analyse, ACARDograph 72 , Peramon Press, Now York, 1964, mp. 208 $26 \%$.

16 Smith, B. Byomstad, P., and Grop, W., Doman Deconpostion -. Parthel Mulahen Methods for Eliptic Partall Diferental Equations, Cambridge Unversity Prese, UK, 1996.

(7) Agoshkow, V. I. and Lebedev, V. I., "Poncare Stektov Operatots and the Methots of Partion of the Dowan in Variational Problems," ComputaWond Processes and Systems, Vol 2 , ed. Marchus,

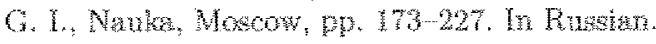

(8) Agohkov, V. I. "Poincré Steklow Operators and Dorman Decomposition Methods in Finite Dhrewe sional Space:" First Interational Symposm on 
Domair Deomposition Methods for Partal Diferentat Equations, eds. Glowinski et al, SAM, Fhiladelphia, pp. $73-112$.

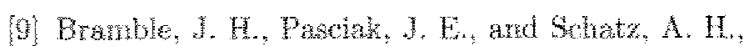
The Conetruction of Precondioners or Ellptic Problem by Substructuring," I. II, III, and IV, Mathematics of Compritation, Vol 47, (17t), 1986 ,

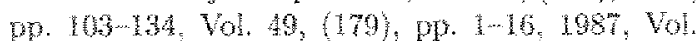
51, (184), pp. 415430, 1988, whl Vol. $53,(187)$. pp. $1-24,1989$

(10) Quarteroni, A. and Vall, A., Domain Decompo.

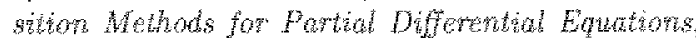
Oxtord Unversity Press, Oxford, UK, 1999.

(1) Tosell, A, and Widund, O., Domain Decomposithon Methody - Algonthms and Theom, Springer Series in Computatonal Mathematcs, SpmingerVerha Berlin Hedelenty, 2005 .

[12] Computers and Structures, Vol. 85, (9), special ism sue on "Hgh Performance Computing for Compltatonal Mechancs:" eds., Magouls, and Top pirg, B. H. V., May 2007, pp $487-562$.

(3) Conputer Methods in Appled Methandes and Ln-

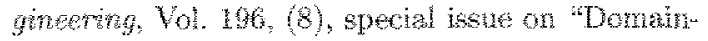
Decomposition Methods: Recent Advases and New Challenges in Tnginering," ods., Masouls, and Rew, D, January 2007 , pp. $1345-1622$

14 Mandel, J, and Dohmann, C. R. "Convergence of a Balancing Domain Decompositon by Constraints and Exergy Minmization," Nomenon Lanear Algebm whit Applications, Vol $10,(7), 2003$, wp. $630 \ldots$ 650 .

[15] Fanhat, $C_{\text {, }}$ Lesoinne, $M_{+}$, and Pierson, $K$, A Scatable Dual-Primal Domain Decomposition Method, Nonerical Lnear Algetra wh Apphou Fons, vol. $7,(7-8), 2000, \mathrm{pg} .687-714$.

[16] Fathat, C., Leoine, N., LeTaller, P., Pierson, K., and Rixen, D., "FETHDP: A Gual-Primal Unifed FET Method - Part I: A Faster Altermatwe to the Two-level FETI Method" Internatorat Jow wat of Nomemol Methods in Engineering, Vol, 50 , pr. $1523-1544.2001$

[17] Mandel, \%, Dohmann, C. A., and Radek, T. "An Agevaie theory for Primal and Din substructurwus Methods by Constrants," Applied Nomench Mathenatice, vol 54, (2), July 2005, pr. $167 \mathrm{~m} 193$.

18) Berdichewsy, V. L., "Vartationd-Asymptoth Method of Constucting a Theory of Shels," Joxt-

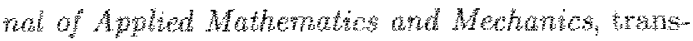

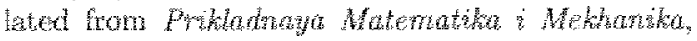
Vol. $43,44,1979$, pp. $664 \cdots 67$

[19] Hodges, D. H. Nonhroar Compogite Bow Theory, A.AA, Reston, $V A, 2006$
20 Volovoi, V. V., and Hodges, D. H., "Theory of Anisotropic Thin-Waled Beams" Jownal of Ap phed Wechantes, Vol. 67 , (3), September 2000, pp. $453+450$.

[21] Ma, W., Hofges, D. H., Volowo, V. V., and Ces nik, C. E. S., On Thwohenkolike Modelnge of Initialy Cured and Twisted Composite Beams,"

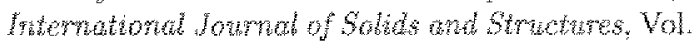
30. (19), September 2002, pp. 5101-5121.

[22] Hodges, D. H., and Yu, W. "A Rigorons, EngreerFriendy Approach for Modelng Realistic, Composite hotor Blades," Wind Thergy, Vol 10, (2), 2007, pp. $170-193$.

29] Wathe, K., Frate Element Procednres in Engher irg Aralyse, Prentice-fall, Ine., NJ, 1982.

(24) Zienkiewicz, O. C., and Taylor, R. L., The Frite: Element Method for Sold and Strotum MechanAcs, Elsevier Butterwoth-Heneman, Oxford, UK, Sixth dition, 2006 .

[25] Le Talle, P., "Donain Decomposition Methods in Computational Mechanics:" Computational Wechanics Advaroes, Vol. 1, (2), 1994, Dp, 121220.

[26] Merant, G., Mtititasking the Conjugate Ga dient methed of the ORAY X-MP/48", Porlet Conzuting, Vol. 5, (3), July 1987, pp. 267 280.

[27 Saad, $Y$. "Krylov Subopace Methods on Supercomputers," SHAM Jotmat on Sointific and Statistical Compitirg, Vol 10, (6). Novernber 1989 , pp. $1200-1232$.

(28) Danel. J. W, Gragg, W. B, Katman, L. and Stewart, G. W., Reorthogotalization and stable Algorthms for Updating the Gran-Schmdt $Q R$ Factorization," Mathenaties of Computation, vol. 30, $(136)$, October 1976, pp. $772-795$.

[29] Giraud, L, Wangou, 3 and Rozioznik, M., The Los of Orthognality in the Gramschmidt Orthogonalation Proces," Computers and Mathemotics whis Aplicoling Vol. 50, (7). October 2005, pp. $1069-1075$. 